\title{
«UNA CIENCIA PARA LA VERDAD Y PARA EL BIEN ». LOS HISTORIADORES DEL CONSEJO SUPERIOR DE INVESTIGACIONES CIENTÍFICAS Y LA INSTITUCIONALIZACIÓN DEL ORDEN ACADÉMICO FRANQUISTA*
}

\author{
«Science for Truth and the Good». The Spanish Council for Scientific \\ Research and the aim to control de historiographic production under de \\ Francoist regime
}

\author{
Alba Fernández Gallego \\ Universidad Complutense de Madrid \\ albafe05@ucm.es \\ Orcid: 0000-0002-0187-2930
}

Recibido: 01-06-2020 - Aceptado: 31-08-2020

Cómo citar este artículo/Citation:

Alba Fernández Gallego, “«Una ciencia para la verdad y para el bien». Los historiadores del Consejo Superior de Investigaciones Científicas y la institucionalización del orden académico franquista", Hispania Nova, 19 (2021): 620 a 660

DOI: https://doi.org/10.20318/hn.2021.5893
Copyright: (c) HISPANIA NOVA es una revista debidamente registrada, con ISSN 1138-7319 y Depósito Legal M 9472-1998. Los textos publicados están -si no se indica lo contrario- bajo una licencia Reconocimiento-Sin obras derivadas 3.0 España de Creative Commons. Puede copiarlos, distribuirlos y comunicarlos públicamente siempre que cite su autor y la revista y la institución que los publica y no haga con ellos obras derivadas. La licencia completa se puede consultar en: http://creativecommons.org/licenses/by-nd/3.0/es/deed.es
Resumen: Este texto aborda la conformación del CSIC en el marco del final de la guerra civil, entendida como una guerra de ocupación. La hipótesis principal es que su creación respondió a la necesidad de crear una institucionalidad propia para un Estado que nació del conflicto. Éste fue la ventana de oportunidad para que cuadros académicos que habían quedado relegados en el periodo anterior, ocupasen las instituciones académicas y de investigación. En primer lugar, se analizarán las rupturas y continuidades del CSIC en relación a las estructuras académicas anteriores y, más concretamente, la Junta para Ampliación de Estudios. En segundo lugar, se estudiarán el discurso oficial impulsado desde el organismo. Por último, se abordará de forma más concreta la producción historiográfica a través del análisis de algunas de las revistas del CSIC

Palabras clave: Ocupación - Orden académico Historiografía - Nacionalcatolicismo - Consejo Superior de Investigaciones Científicas. 
Abstract: This paper addresses the configuration of the CSIC within the framework of the end of the Civil War, which cab understood as occupation warfare. The main hypothesis is that its creation responded to the need of a State to create its own institutionality as it was born during a conflict. This meant the opportunity to occupy the academic and research institutions for the academic staff that had been relegated during the previous decades. Firstly, my article will analyze the breakdowns and continuities at CSIC in relation to the academic background and, concretely, to the Junta para Ampliación de Estudios. Secondly, the official discourses launched by the institution will be examined. Finally, historiographic production will be addressed more concretely by examining some CSIC journals

Keywords: Occupation - Academic order Historiography - Nationalcatholicism - Spanish Council for Scientific Research.

\section{INTRODUCCIÓN}

Probablemente el CSIC deba ser considerado el mayor logro alcanzado por laicos de la Iglesia católica en el desarrollo científico universal del siglo XX [...] El CSIC superó con creces la tarea de promoción de investigación multidisciplinar, descentralizada, internacionalizada y en interacción con las universidades que su inmediato antecesor, la JAE, había logrado. Pero es que además dio muchas más pensiones que ésta y consiguió su histórico logro de institucionalizar la profesión de científico en España [...] Una prueba irrefutable de que ciencia y religión, o razón y fe, han sido compatibles en la España del siglo XX, y si lo han sido es porque de hecho lo son ${ }^{l}$.

El 75 aniversario de la creación del Consejo Superior de Investigaciones Científicas (CSIC) llegó envuelto en polémica. Algunos de sus investigadores calificaron al organismo como el mayor logro científico del siglo XX, lo consideraron heredero director de la Junta para Ampliación de Estudios (JAE) e incluso lo pusieron de ejemplo de cómo la compatibilidad entre ciencia y religión, razón y fe, es todavía

\footnotetext{
* Este trabajo ha sido realizado en el marco del Proyecto de investigación PGC2018-096461-B-C41, titulado "La sociedad urbana en España, 1860-1983. De los ensanches a las áreas metropolitanas, cambio social y modernización".

${ }^{1}$ Entrevista realizada a Alfonso V. Carrascosa, doctor en Ciencias Biológicas por la Universidad Complutense de Madrid y científico del CSIC, por el periódico Religión en Libertad, el 30 de julio de 2014 http://www.religionenlibertad.com/articulo.asp?idarticulo=36959
} 
«Una ciencia para la verdad y para el bien ». Los historiadores del Consejo Superior de Investigaciones Cientificas y la institucionalización del orden académico franquista

posible hoy día. Otros cuestionaron que éste debiese ser un momento de celebración, considerando que su creación no significó sino el momento en que la ciencia fue "barrida de España". . Desde la propia institución se afirmó que "a punto de cumplir 75 años de andadura, Editorial CSIC continúa trabajando para que el brillante y riguroso legado de la Junta para la Ampliación de Estudios, heredado y ampliado por la Agencia Estatal Consejo Superior de Investigaciones Científicas, permanezca como medio de difusión del conocimiento científico y la actividad investigadora" ${ }^{3}$.

El hecho de que, a día de hoy, la relación entre la JAE y el CSIC siga siendo objeto de confrontación con discursos tan dispares, indica la necesidad de volver sobre ese pasado con una nueva mirada. ¿Cómo explicar (y asumir) esa conflictiva continuidad entre los organismos? Si atendemos al espacio físico y los recursos materiales, el Consejo fue heredero de la Junta desde el momento en que se traspasaron a él todos sus servicios en 1938. Momento en el que, debe recordarse, la JAE seguía existiendo y funcionando dentro del aparato estatal republicano. Si atendemos al plano intelectual, la herencia es, ciertamente, inexistente, al menos en la definición de su proyecto. Así, acercarse al CSIC de posguerra nos permite apreciar toda una serie de rupturas y continuidades que hacen del tránsito de una institución a otra un proceso de gran complejidad.

Si comprendemos el franquismo como un régimen político surgido en el marco de una guerra de ocupación, debemos atender a la trascendencia que en la época se otorgó a la legitimación de su presencia, acción y naturaleza desde las instituciones culturales. Así, el presente texto intenta complejizar el proceso de legitimación de los regímenes autoritarios a través de la ocupación de los centros académicos y de investigación. A priori, la secuencia podría parecer simple: acceder a estos espacios para orientar su actuación en defensa de un régimen político concreto. Sin embargo, el ejemplo del franquismo y el contexto posconflicto en que surgió el CSIC permite formular otras preguntas. Para ilustrar este proceso el análisis se centrará en la creación del Consejo y, más concretamente, de sus institutos de historia, durante la inmediata posguerra. ¿De qué maneras el CSIC, sus autoridades y sus historiadores contribuyeron

\footnotetext{
2 Artículo de Jorge M. Reverte en el diario El País, el 4 de septiembre de 2014: https://elpais.com/elpais/2014/09/03/opinion/1409732798 975176.html

${ }^{3}$ Editorial CSIC, Catálogo CSIC 2014, (Madrid: CSIC, 2014), 3.
} 
a la legitimación intelectual de la dictadura franquista y en qué medida esto se materializó en la práctica?

La hipótesis de partida es que, por un lado, la construcción del CSIC respondió a la necesidad de crear una institucionalidad propia para un Estado surgido de una guerra civil. Por otro, que existió un desfase entre la práctica historiográfica en los institutos de historia y los discursos oficiales en torno a la creación y desarrollo del CSIC, tanto en las raíces de su legitimación como en los ejes de su orientación interna. Entendemos por práctica historiográfica el conjunto de recursos humanos y materiales que explican la producción de las distintas escuelas historiográficas, sus relaciones socio-profesionales, así como los canales de comunicación establecidos (desde congresos a revistas) y la instauración de unos criterios para la praxis de la disciplina ${ }^{4}$. En este caso concreto, si bien se promovió una ruptura total con el periodo anterior en el plano intelectual y discursivo, también se produjeron una serie de continuidades tanto a nivel material como de dichas prácticas, que hicieron de la relación con su pasado inmediato un proceso algo complejo. Así, las siguientes páginas pretenden debatir con algunas de las visiones que se han planteado respecto a la llamada «hora cero» en la historiografía franquista, ligada a una clara quiebra con lo anterior. Sin embargo, no pueden olvidarse importantes persistencias que explican la práctica de la profesión después de la Guerra Civil.

En primer lugar, se abordarán las rupturas y continuidades institucionales que hubo entre la JAE y el CSIC. Éste se reclamó como un organismo de nuevo cuño, definiéndose en clara oposición a lo anterior, lo que concuerda con las aproximaciones que han explicado el franquismo como la institucionalización política de la reacción a los cambios producidos en la sociedad española desde principios del siglo $\mathrm{XX}^{5}$. Sin

\footnotetext{
${ }^{4}$ En este sentido, Marín Gelabert distingue entre práctica histórica y práctica historiográfica. Para las definiciones que este autor plantea, véase: Miquel Marín Gelabert, "Historiadores locales e historiadores universitarios. La historiografía española en su contexto internacional, 1948-1965", en Lecturas de la Historia. Nueve lecciones sobre Historia de la Historiografia, coord. por Carlos Forcadell e Ignacio Peiró (Zaragoza: Institución Fernando El Católico, 2001), 105. Desde otro punto de vista, Ricouer habla de operación historiográfica, partiendo de las premisas expuestas por Michel de Certeau. Véase Paul Ricoeur, La memoria, la historia, el olvido (Madrid, Trotta, 2010), 179-193.

5 En términos de orden público, véase Alejandro Pérez-Olivares, "La victoria bajo control: ocupación, orden público y orden social del Madrid franquista (1936-1948)" (Tesis doctoral, Universidad Complutense de Madrid, 2017). https://eprints.ucm.es/45481/ . En términos académicos, Luis Enrique Otero Carvajal (dir.), La destrucción de la ciencia en España. Depuración universitaria en el franquismo
} 
embargo, es importante recordar que muchos de los discursos que proponían no eran novedosos, sino que provenían de las disputas que los intelectuales del siglo XIX habían sostenido ya, especialmente del enfrentamiento entre regeneracionistas y los defensores de las ideas ultramontanas de Marcelino Menéndez Pelayo ${ }^{6}$. Por ello el texto ahondará en la definición que las autoridades responsables de la creación del CSIC establecieron de su pasado enemigo, así como la relación que establecieron con él en el despliegue operativo de la institución.

En segundo lugar, se analizarán los discursos que se impulsaron desde la oficialidad del organismo. En los primeros años de la década de los cuarenta distintas fuerzas políticas y culturales se enfrentaron por imponer su visión sobre la construcción del régimen, desde ACNP, Acción Católica o el Opus Dei, hasta Falange ${ }^{7}$. En el plano cultural y científico el nacionalcatolicismo fue el modelo triunfante, y el CSIC lo proyectó de diferentes formas. Por un lado, a través de la legislación y la serie de discursos inaugurales donde se presentó la definición del proyecto. Por otro, a través de la arquitectura y el espacio, en una suerte de construcción del cuerpo de la nación ${ }^{8}$, donde ciencia y fe se unían en lo material. Por último, se puede rastrear en la dimensión pública que tuvo la cultura franquista, tanto en las actividades de los investigadores del Consejo a nivel individual como de forma más organizada a través de sus publicaciones periódicas.

En tercer lugar, se abordará de forma concreta la producción historiográfica. Las revistas de los distintos institutos se conformaron como plataformas de difusión: fueron el medio de dar a conocer su actividad a la comunidad internacional y poder expresar su práctica historiográfica. A partir de ahí se cuestionará cómo se llevó a cabo esa práctica y si los investigadores tenían alguna capacidad de agencia frente al discurso público. Al fin y al cabo, muchos de los historiadores del franquismo, al menos los que ocuparon los

(Madrid: Editorial Complutense, 2006) y Jaume Claret, El atroz desmoche: la destrucción de la universidad española por el franquismo (Barcelona: Crítica, 2006). En términos económicos, Carlos Barciela, Inmaculada López, Joaquín Melgarejo y José Antonio Miranda, La España de Franco (19391975). Economía (Madrid: Síntesis, 2001).

6 José María López Sánchez, Heterodoxos españoles. El Centro de Estudios Históricos, 1910-1936 (Madrid, Marcial Pons Historia / Consejo Superior de Investigaciones Científicas, 2006).

${ }^{7}$ Ismael Saz, España contra España. Los nacionalismos franquistas (Madrid: Marcial Pons, 2003).

8 Zira Box, "El cuerpo de la nación. Arquitectura, urbanismo y capitalidad en el primer franquismo", Revista de Estudios Politicos, no 155 (enero-marzo de 2012): 151-181. 
cargos más relevantes al comienzo del CSIC, habían estado insertos en las estructuras académicas anteriores a la guerra y, por tanto, muchas veces asentaron su trabajo en prácticas ya institucionalizadas. Quizás esto nos ayude a definir mejor la relación entre JAE y CSIC, comprendida desde el prisma de ocupación de unas estructuras académicas que la guerra civil hizo posible. A partir de ahí cobraron sentido las bases que conformaron el nuevo orden académico de posguerra representado por el CSIC.

\section{RUPTURAS Y CONTINUIDADES: UNA ¿NUEVA? INSTITUCIÓN PARA LA CIENCIA}

Anhelamos, en primer término, una ciencia rigurosamente tal, en la plenitud de su concepto lógico; una ciencia dotada de un intrínseco sistema y armonía, y apoyada fundamentalmente en la ecuación tomista, esto es, una ciencia para la verdad y para el bien. Quedan ya para siempre al margen de la esfera de nuestra actividad cientifica los esfuerzos intelectuales que caminen por sendas de error. Los errores no pueden constituir ciencia, ni existe para ellos libertad científica. Nuestra ciencia es exclusivamente para la verdad, la única que -al decir del Apóstol- nos hace libres y la que, llevándonos de la mano a la causa altísima y primera, nos permite atisbar los secretos de la Divina Sabiduría?.

El CSIC, creado el 24 de noviembre de 1939, celebró su inauguración oficial casi un año después. El nuevo organismo respondía a un proyecto claro y bien definido. Las palabras de José Ibáñez Martín, en cuya persona se aunaban los cargos de Ministro de Educación Nacional y Presidente del CSIC, reflejan algunos pilares de este proyecto. Apoyándose en la tradición escolástica y, de manera concreta, el tomismo, defendió una ciencia "para la verdad y para el bien"10. Así se criticaba al positivismo y se reclamaba

\footnotetext{
${ }^{9}$ Discurso de José Ibáñez Martín en el acto inaugural del Consejo Superior de Investigaciones Científicas el 30 de octubre de 1940. CSIC, Memoria de la Secretaría General, 1940-1941, pp. 31-32.

${ }^{10}$ Para el uso del tomismo en las memorias de oposición a cátedra de Medicina, Filosofía o Derecho Político: José María López Sánchez, "La medicina en la universidad nacionalcatólica”, en La universidad nacionalcatólica, ed. por Luis Enrique Otero (Madrid: Dyckinson, 2014), 317-476; Rubén Pallol, "La Filosofía en la universidad nacionalcatólica", en La universidad nacionalcatólica, ed. por Luis Enrique Otero (Madrid: Dyckinson, 2014), 477-534; Javier SAN ANDRÉS, "El Derecho Político en la
} 
la religión y la ortodoxia como máximas garantías científicas. La fe se convertía, más que la razón, en el instrumento de conocimiento. Esta referencia invocaba también la existencia de un orden natural que debía mantenerse. Como proseguía su discurso, cualquier error debía quedar al margen, no debía haber para éstos libertad científica. Sus intenciones como ministro, plasmadas también como presidente del CSIC, eran prueba de las bases a partir de las cuales pretendía estructurar un nuevo orden académico.

La construcción del CSIC respondió a la necesidad de crear una institucionalidad propia para un Estado surgido de una guerra civil. Algo similar ocurrió en Italia y Alemania en sus periodos totalitarios, momentos en los que se propugnó una fuerte centralización, una dependencia casi total del ministerio y una autonomía universitaria inexistente $^{11}$. En el caso español, por ejemplo, la personalidad de Ibáñez Martín aunando en su figura dos cargos tan relevantes, no sólo aseguró el vínculo entre educación e investigación, también la dependencia del devenir de las cátedras universitarias. Mientras en España se pretendió mantener un férreo control ideológico y aceptar en sus instituciones sólo a aquellos investigadores afines al régimen, en Italia la mayor parte del profesorado que provenía de la universidad se mantuvo hasta 1938, cuando la promulgación de las leyes raciales significó una depuración que afectó al conjunto de sus profesionales. En España, el peso principal recayó en el nacionalcatolicismo, lo que empezó a tomar forma ya durante la guerra.

Desde la Junta Técnica del Estado en 1937 y el primer gobierno de Burgos en 1938, a la oficialidad del 1 de abril del 39, se fue forjando un nuevo orden que asentó progresivamente la dominación tras el final de la guerra. Pero la posguerra no puede comprenderse como una tabula rasa, sino que estuvo impregnada de rupturas y continuidades que fueron conformando un nuevo orden de cosas ${ }^{12}$. Este es el contexto

universidad nacionalcatólica", en La universidad nacionalcatólica, ed. por Luis Enrique Otero (Madrid: Dyckinson, 2014), 775-896.

${ }^{11}$ Francisco Morente, "La universidad fascista y la universidad franquista en perspectiva comparada", Cuadernos del Instituto Antonio de Nebrija de Estudios sobre la Universidad, $\mathrm{n}^{\circ} 8$ (2005): 179-214; Albertina Vittoria, "L'Università italiana durante il regime fascista, controllo governativo e attività antifascista", en La universidad española bajo el régimen de Franco (1939-1975), ed. por Juan José Carreras y Miguel Ángel Ruiz (Zaragoza: Institución Fernando el Católico, 1991), 29-62.

${ }^{12}$ Sobre las rupturas y continuidades que operaron durante la Guerra Civil y después, puede verse Daniel Oviedo y Alejandro Pérez-Olivares, Madrid, una ciudad en guerra (1936-1948) (Madrid, Los libros de la Catarata, 2016). La progresiva construcción del orden público y el orden social en la posguerra y su 
desde el que se propone comprender la creación del CSIC: se erigió como un organismo de nuevo cuño que pretendía una ruptura completa y radical con el pasado inmediatamente anterior, sobre todo republicano. En el campo científico, la institución a batir fue la JAE. Su misión fue la de marcar las pautas del orden académico del nuevo Estado franquista. Esta ruptura estuvo ligada a la guerra como una ventana de oportunidad para todos aquellos que habían sido desplazados o relegados en el mundo académico del primer tercio de siglo y que ahora, por fin, podían recuperar el poder que reclamaban como legítimo. Las primeras leyes que desmontaban el sistema anterior, decretando la depuración del personal docente y poniendo fin a la actividad de la JAE, fueron promulgadas antes incluso de la finalización de la guerra, dentro de las lógicas del proceso de creación de un nuevo Estado ${ }^{13}$.

Todas estas rupturas han hecho que tanto la creación del CSIC como la actividad de sus historiadores se consideren como la manifestación de una «hora cero» ${ }^{14}$. Ésta, entendida como un momento traumático de quiebra, no debe invisibilizar las continuidades de las que se vio acompañada. Muchos de los principios que inspiraron la creación del CSIC no eran novedosos: habían formado parte del horizonte ideológico y cultural de los sectores más integristas y conservadores del mundo académico e intelectual desde hacía varias décadas y bebían directamente de las teorizaciones del siglo XIX. Simplemente, no habían podido institucionalizarse, y el final de la guerra fue el momento propicio para ello.

La animadversión hacia la JAE se debió al espacio que ésta ocupó, especialmente en términos simbólicos: su protagonismo en la vida científica del país eclipsó cualquier otra propuesta. Nació en 1907, dependiente del Estado, aunque con gran autonomía. Su misión fue la de dar un impulso científico a España a través de la formación de investigadores y docentes en el extranjero mediante un sistema de

relación con la ocupación en Alejandro Pérez-Olivares, Madrid cautivo. Ocupación y control de una ciudad (1936-1948) (Valencia: PUV, 2020).

${ }^{13}$ Christina Steenkamp, Violence and Postwar Reconstruction. Managing Insecurity in the Aftermath of Peace Accords (London: New York, Tauris, 2009).

${ }^{14}$ Ignacio Peiró, Historiadores en España. Historia de la Historia y memoria de la profesión (Zaragoza: Prensas de la Universidad de Zaragoza, 2013), 37-51; Miquel Marín Gelabert, "Revisionismo de Estado y primera hora cero en España, 1936-1943”, en El pasado en construcción. Revisionismos históricos en la historiografía contemporánea, ed. por Carlos Forcadell, Ignacio Peiro y Mercedes Yusta (Zaragoza: Institución Fernando el Católico, 2015), 387-388. 
pensiones; la fundación de una serie de centros de investigación con el fin de formar una sólida red científica; y la creación de centros experimentales de educación para todos los niveles ${ }^{15}$. El proyecto supuso un éxito y la JAE simbolizó el desarrollo científico en España, uno más acorde a la modernidad europea. Sus miembros consideraban que la aportación española a la ciencia universal en los últimos siglos había sido mínima, debido a un fuerte componente religioso en la sociedad española y a la imposibilidad de conciliarlo con el libre ejercicio de la investigación científica. Esta concepción fue la que pusieron en práctica los historiadores que realizaron sus investigaciones en el CEH de la Junta. A través de su labor trataron de comprender y definir una esencia o personalidad de la nación española, en cuyo núcleo situaban a Castilla, que adquirió una personalidad histórica propia ${ }^{16}$.

El CSIC se diseñó desde un principio en clara oposición a ese modelo. $\mathrm{Su}$ proyecto intelectual se reivindicó heredero de las ideas de Marcelino Menéndez Pelayo, quien había dirigido la Real Academia de la Historia. En su cátedra en la Universidad Central formó a destacados intelectuales como Ramón Menéndez Pidal, director del $\mathrm{CEH}$, al que terminó enfrentándose intelectualmente ${ }^{17}$. Menéndez Pelayo creía necesario reivindicar un pasado intelectual nacional y proponía la conciliación entre razón y fe: si bien la primera debía ajustarse a la segunda, en ningún caso podía quedar anulada $^{18}$. Un importante grupo de intelectuales mantuvieron esta posición durante el primer tercio del XX, alimentando la idea de una ciencia católica ${ }^{19}$ : compartieron un programa cultural cuyo origen se encontraba en corrientes irracionalistas, establecieron el papel nuclear de la religión católica, la no plena aceptación de uno de los pilares de la

\footnotetext{
15 José García Velasco y José Manuel Sánchez Ron, 100 JAE. La Junta para Ampliación de Estudios e Investigaciones Cientificas en su centenario. Actas del II Congreso Internacional, celebrado los días 4, 5 y 6 de febrero de 2008 (2 vol.) (Madrid: Residencia de Estudiantes, 2010).

16 José María López Sánchez, "Ciencia y cultura en el Centro de Estudios Históricos de Madrid, 19101936”, Circunstancia: Revista de Ciencias Sociales del Instituto Universitario de Investigación Ortega y Gasset, n 14 (2007).

${ }^{17}$ La pugna de ambas escuelas filológicas en la posguerra en Rubén Pallol, "Menéndez contra Menéndez. Represión y resistencia de los discípulos de Menéndez Pidal ante la ofensiva intelectual tradicionalista de posguerra en la universidad española", Cuadernos de historia contemporánea, 38 (2016): 285-299.

18 Antonio Santoveña Setién, "Una alternativa cultural católica para la España de la Restauración: Menéndez Pelayo y la polémica sobre la ciencia", Investigaciones históricas: Época moderna y contemporánea, 12 (1992): 252.

${ }^{19}$ Para una reflexión sobre el concepto de ciencia católica, véase: José María López Sánchez, “Científicos e intelectuales, una nueva cultura política: José Cuatrecasas y las colecciones de flora tropical”, Asclepio. Revista de Historia de la Medicina y de la Ciencia 71/2 (2019): 277-291.
} 
racionalidad ilustrada. Opuestos a las nuevas corrientes de modernidad europea, ese grupo fue perdiendo relevancia y poder académico. Lejos de resolverse el conflicto, siguió latente y oculto por los logros de la ciencia española de comienzos de $\operatorname{siglo}^{20}$. La sublevación de 1936 lo evidenció abruptamente, abriendo una ventana de oportunidad para imponer su concepto de ciencia y permitir ponerlo en práctica, así como para recuperar el papel que, según ellos, les correspondía dentro de las estructuras de poder científico $^{21}$.

La lucha por el control de la ciencia y la educación fue una preocupación común tanto para la República como para los sublevados. En mayo de 1938 el gobierno de Burgos disolvió la JAE y traspasó sus servicios al Instituto de España. Éste, creado para coordinar las Reales Academias, fue ideado por Eugenio D'Ors ${ }^{22}$. La estructura y su devenir reflejaron la complejidad del momento. Manuel de Falla fue nombrado Presidente y Pedro Sáinz Rodríguez Vicepresidente ${ }^{23}$, pero la presencia del primero fue meramente simbólica ${ }^{24}$ y en 1939 huyó al exilio. El primer presidente efectivo fue Leopoldo Eijo y Garay, Arzobispo de Madrid y Comisario nacional de F.E.T. y de las J.O.N.S. entre 1943 y $1946^{25}$. Próximo al Opus Dei, cuyos intereses protegió desde el comienzo, formó parte de la estructura del CSIC dirigiendo el Instituto "Francisco

\footnotetext{
${ }^{20}$ José María López Sánchez, "Los estudios históricos en la Facultad de Filosofía y Letras", en La Facultad de Filosofia y Letras en la Segunda República. Arquitectura y universidad durante los años treinta, ed. por Santiago López Ríos y Jun Antonio González Cárceles (Madrid: Universidad Complutense de Madrid-Sociedad Estatal de Conmemoraciones Culturales, 2008), 408-415.

${ }^{21}$ Alba Fernández, "Poder académico en el CSIC: una larga espera", en La alargada sombra del franquismo. Naturaleza, mecanismos de pervivencia y huellas de la dictadura, coord. por Asunción Esteban Recio, Dunia Etura y Mateo Tomasoni (Editorial Comares, 2019 [CD]), 89-109.

${ }^{22}$ D’Ors fue nombrado Secretario perpetuo. Véase: Juan Manuel Reol Tejada, "El Instituto de España y las Reales Academias", Arbor: Ciencia, pensamiento y cultura, $\mathrm{n}^{\circ} 641$ (1999): 1-18.

${ }^{23}$ Decreto de 1 de enero de 1938, Boletín Oficial del Estado, $n^{\circ} 438,2$ enero 1938, p. 5.075.

${ }^{24}$ Algunos estudios afirman que se negó a tomar posesión de su cargo, y otros declaran que no le fue posible incorporarse para hacerlo efectivo. Véase José Peña González, "El Instituto de España: pasado y presente", Boletín de la Real Academia de Córdoba de Ciencias, Bellas Letras y Nobles Artes, $\mathrm{n}^{\circ} 153$ (2007): 301-303; Manuel Jesús González, "Periplo histórico del Instituto de España", Sesión conmemorativa de la fundación del Instituto de España. Celebrada el 4 de febrero de 2009 (Madrid: Instituto de España, 2010).9.

${ }^{25}$ Santiago Martínez Sánchez, "Los obispos españoles ante el Opus Dei, 1939-1946", Studia et Documenta: Rivista dell'Istituto Storico san Josemaría Escrivá, vol. XIV, ${ }^{\circ} 14$ (2020): 217-286. La figura de Eijo y Garay ha sido abordada por Santiago Mata, "Leopoldo Eijo y Garay (1878-1963)" (Tesis doctoral, Universidad de Navarra, 1996).
} 

institucionalización del orden académico franquista

Suárez" de Teología ${ }^{26}$. En su figura también confluyeron varios cargos, en la línea de la concentración del poder y la vinculación personal entre las distintas instituciones de un régimen aún en construcción. Un caso paradigmático fue el de Julio Palacios Martínez, nombrado Vicepresidente en abril de $1939^{27}$. Catedrático de Física en la Universidad Central y antiguo vocal de la JAE, participó durante la guerra como miembro del Servicio de Información y Policía Militar (SIPM), el servicio de espionaje franquista ${ }^{28}$. Colaboró activamente en la acción de Besteiro ante Casado para la rendición de Madrid, por lo que tuvo como premio el olvido de un pasado unido a la JAE y sus nombramientos en el Instituto de España, como Vicerrector de la Universidad Central y en la dirección de los Centros de Ciencias físico-matemáticas y Naturales de Madrid ${ }^{29}$.

El poder del Instituto duró poco: una orden de abril de 1940 traspasaba al recién creado CSIC todos los servicios de la extinta JAE, lo que supuso el vaciamiento de funciones del Instituto ${ }^{30}$. Este traspaso se produjo una vez que Sainz Rodríguez había sido ya destituido como Ministro de Educación y, en su lugar, se había nombrado a José Ibáñez Martín. Muy cercano al Opus Dei, fue el primer presidente del CSIC, y durante su ministerio, hasta su destitución en 1951, favoreció el acceso de los investigadores del CSIC a las cátedras universitarias ${ }^{31}$. Fue el CSIC quien terminó estableciéndose como "órgano supremo de la alta cultura española, en el que tienen su elevada representación los más prestigiosos elementos universitarios, académicos y técnicos, gozará de la máxima jerarquía en la vida cultural del país. Alcanzará, por tanto, el puesto más

\footnotetext{
${ }^{26}$ CSIC, Memoria de la Secretaría General, 1940-1941, p. 121.

${ }^{27}$ Decreto de 26 de abril de 1939, Boletín Oficial del Estado, $n^{\circ} 118,28$ abril 1939, p. 2.278.

${ }^{28}$ Carlos Píriz González, "En campo enemigo: la Quinta Columna en la Guerra Civil española (c. 19361941)" (Tesis doctoral, Universidad de Salamanca, 2019), 477, 507 y 571.

${ }^{29}$ Orden de 1 de mayo de 1939, Boletín Oficial del Estado, $n^{\circ} 126,6$ mayo 1939, p. 2.473.

${ }^{30}$ Orden de 18 de abril de 1940, Boletín Oficial del Estado, $n^{\circ} 119,28$ abril 1940, p. 2.898.

31 Jaume Claret, "Cuando las cátedras eran trincheras. La depuración política e ideológica de la Universidad española durante el primer franquismo", Hispania Nova: Revista de Historia Contemporánea, $\mathrm{n}^{\circ}$ 6, (2006); Rubén Pallol, Javier San Andrés y Alba Fernández, "De asaltos y conquistas. El papel de las redes en las oposiciones a cátedras de universidad en el primer franquismo (1940-1951)", en La alargada sombra del franquismo. Naturaleza, mecanismos de pervivencia y huellas de la dictadura coord. por Asunción Esteban Recio, Dunia Etura y Mateo Tomasoni (coords.) (Granada: Editorial Comares, 2019 [CD]), 1000-1022.
} 
preeminente en las manifestaciones sociales y públicas de cultura de la esfera nacional y en las relaciones con el mundo científico exterior" ${ }^{32}$.

Aún antes del control de las instituciones, se definió también el aparato de control del personal investigador y docente mediante un proceso de depuración, muestra de cómo el Estado franquista sentó sus bases desde el primer momento de la sublevación. En julio de 1936 se creó la Junta de Defensa Nacional, en octubre la Junta Técnica del Estado, y finalmente la Comisión de Cultura y Enseñanza, presidida por José María Pemán ${ }^{33}$. En noviembre se instituyeron también las Comisiones Depuradoras del personal de la Enseñanza Media ${ }^{34}$. El marco de actuación quedó definitivamente establecido con la Ley de Responsabilidades Políticas del 10 de febrero de 1939, que fijó las normas para la depuración de todos los funcionarios públicos. Todos los investigadores debieron someterse a este proceso, y solo quien lo pasó favorablemente pudo formar parte del nuevo orden académico. El resto tuvieron que marcharse al exilio o buscar otras salidas profesionales que nos les estuviesen vetadas.

Paralelamente a la construcción de nuevas estructuras para la ciencia y la cultura, el nuevo Estado debía decidir qué hacer con un pasado que le resultaba incómodo. La intención con la ILE era clara: "podría arrasarse la edificación, sembrar de sal el solar” ${ }^{35}$. El 29 de abril de 1939 la Columna de Orden y Policía de Ocupación registraba la sede de la ILE, en el Paseo del General Martínez Campos, y requisaba la biblioteca de Manuel Bartolomé Cossío ${ }^{36}$. El destino de la JAE se planteó de forma más tibia, ya que su relevancia cultural internacional no hacía posible el silencio. Sus atribuciones

\footnotetext{
${ }^{32}$ Orden de 8 de marzo de 1940 disponiendo que el CSIC gozará de la máxima jerarquía en la vida cultural del país, Boletín Oficial del Estado, no 78, 28 de marzo de 1940, p. 1897.

${ }^{33}$ Gutmaro Gómez Bravo, "Del expediente de depuración y otras responsabilidades", en La destrucción de la ciencia en España. Depuración universitaria en el franquismo dir. por Luis Enrique Otero Carvajal (Madrid: Editorial Complutense, 2006), 149-176.

${ }^{34}$ Jaume Claret, El atroz desmoche...

${ }^{35}$ Ángel González, "La herencia de la Institución Libre de Enseñanza", en Una poderosa fuerza secreta. La Institución Libre de Enseñanza ed. por AAVV (San Sebastián: Editorial Española, 1940), 273.

36 Centro Documental de la Memoria Histórica (CDMH). Delegación Nacional de Servicios Documentales. Secretaría General. Delegación de Madrid. Caja 46, expediente 2, libro de registros, p. 9. Agradezco a Alejandro Pérez-Olivares que me haya proporcionado esta fuente. Para la Columna de Orden y Policía de Ocupación en Madrid véase: Alejandro Pérez-Olivares, "Objetivo Madrid: planes de ocupación y concepción del orden público durante la guerra civil española". Culture \& History Digital $\begin{array}{lllll}\text { Journal, } & \mathrm{n}^{\mathrm{o}} & 4 & \text { (2), }\end{array}$ http://cultureandhistory.revistas.csic.es/index.php/cultureandhistory/article/view/84/298.
} 
recayeron en el CSIC. Pero la relación entre ambas fue más compleja que un simple traspaso de poderes. Su legado intelectual fue denostado por el nacionalcatolicismo imperante, por lo que el CSIC no podía, ni pretendía, reclamarse su heredero. Contrariamente, el legado material sí fue aprovechado en su totalidad: edificios, mobiliario e incluso algunos proyectos en marcha que luego sería reapropiados y/o resignificados. También hubo algunas continuidades entre su personal, normalmente en cargos de carácter más técnico ${ }^{37}$.

En lo concerniente al espacio físico, el Instituto-Escuela sirvió durante unos meses como cárcel de mujeres provenientes de la prisión de Ventas y en la posguerra fue rebautizado como Instituto Ramiro de Maeztu, adaptando su programa a los nuevos tiempos $^{38}$. La Residencia sirvió durante la guerra de refugio antiaéreo, y también albergó un hospital de carabineros dirigido por el doctor Luis Calandre. Los edificios científicos sí fueron reutilizados por el CSIC. El Instituto Nacional de Física y Química pasó a llamarse Instituto de Química Física Rocasolano y el CEH terminó albergando la biblioteca científica del CSIC y el Patronato Menéndez Pelayo ${ }^{39}$, que vino a cubrir los campos del CEH dentro de las Humanidades. También en la Colina de los Chopos el antiguo auditorio de la Residencia de Estudiantes y el Instituto-Escuela fue convertido en la Iglesia del Espíritu Santo. La ocupación del espacio físico muestra cómo, ya desde los inicios de la guerra, se estaba luchando por controlar el sentido que debían tomar la cultura y la ciencia, planteando una definición muy concreta de ella a través de la creación de un nuevo proyecto: el CSIC ${ }^{40}$. Como exponía Ibáñez Martín en su discurso, ese pasado era un error para el que ya no había sitio, debía quedar relegado y olvidado. El análisis del devenir de estos organismos, su personal y sus espacios ha demostrado, sin embargo, que la relación fue más compleja. Las necesidades materiales y la práctica investigadora obligaron al CSIC a dar continuidad al proyecto anterior en aspectos

\footnotetext{
37 Alba Fernández Gallego, "La construcción del Instituto Jerónimo Zurita: un estudio de caso del Consejo Superior de Investigaciones Científicas en la posguerra (1939-1951)", Cuadernos de Historia Contemporánea, vol. 37 (2015): 257-280.

${ }^{38}$ Fernando Hernández Holgado, "La prisión militante: las cárceles franquistas de mujeres de Barcelona y Madrid (1939-1945)” (Tesis doctoral, Universidad Complutense de Madrid, 2011), 255-262.

${ }^{39}$ CSIC, Memoria de la Secretaría General, 1940-1941, pp. 281 y 305 respectivamente.

40 Para una reflexión sobre la conformación de distintas culturas asentadas en el conflicto, y más concretamente para la cultura de la victoria, véase Claudio Hernández Burgos, "De la cultura de guerra a la cultura de la victoria: los vencedores y la construcción de la dictadura franquista (1936-1951)", Pasado y Memoria: Revista de Historia Contemporánea, $\mathrm{n}^{\circ} 15$ (2016): 123-148.
} 
relativos a su patrimonio material, a su capital humano, e incluso en ocasiones a las propias prácticas de la profesión.

En su clásico estudio sobre ocupaciones, Carlton plantea dos escenarios posibles ante una ocupación: que el poder dominante opte por permitir la continuación de la actividad anterior de forma similar con algún tipo de gravamen, o que imponga nuevas constituciones a pesar de la reticencia. En el caso del CSIC no podemos hablar claramente de una u otra. Sin embargo, podría considerarse una suerte de reconstitucionalización al menos en sus planteamientos ${ }^{41}$ : sí se quiso imponer un nuevo orden académico, surgido directamente del conflicto. A la hora de llevarlo a cabo hubo que terminar por aceptar algunas continuidades con respecto al orden anterior, con el fin de asegurar su supervivencia. Debemos entenderlo en el contexto de un franquismo que no fue monolítico, donde existían distintas fuerzas reaccionarias que luchaban por alcanzar cotas de poder en el aparato del nuevo Estado: el franquismo fue evolucionando a través de esta pugna ${ }^{42}$. El Opus Dei fue uno de los grandes beneficiados en el nuevo orden académico de posguerra, y se legitimó a través de discursos institucionales, la implantación de nuevas prácticas (en la producción científica) y la resignificación de espacios.

\section{UN ORDEN ACADÉMICO NACIONALCATÓLICO: DE LA DEFINICIÓN A LA DIFUSIÓN}

En la estructura de poder del franquismo coexistieron grupos reaccionarios y contrarrevolucionarios, un fenómeno que según Philippe Burrin puede denominarse "compromiso autoritario" $" 43$ y que se extendió por gran parte de las dictaduras antiliberales y antidemocráticas del siglo XX. Si la Guerra Civil puede ser entendida como una guerra de ocupación, ésta incluyó, en un sentido amplio, la lucha por el

\footnotetext{
41 Para las posibilidades que ofrece este concepto en contextos de ocupación, véase Eric Carlton, Occupation. The policies and practices of military conquerors (London: Routledge, 2002), 55-68.

${ }^{42}$ Zira Box, "La dictadura franquista: culturas políticas enfrentadas dentro del régimen vencedor", en Del franquismo a la democracia, 1936-2013 coord. por Manuel Pérez Ledesma e Ismael Saz (Madrid: Marcial Pons, Zaragoza: Prensas de la Universidad de Zaragoza, 2015), 239-265. Para el enfrentamiento entre los sectores católicos y el falangista véase: Ismael Saz, España contra España...; Ismael Saz, "Falangistas y católicos reaccionarios: una batalla político-cultural decisiva", en La España de los cincuenta ed. por Abdón Mateos (Madrid: Eneida, 2008), 237-250.

${ }^{43}$ Philippe Burrin, Fascisme, nazisme, autoritarisme (París, Le Seuil, 2000).
} 
control de la ciencia, la educación y la cultura. El estudio de las instituciones académicas no escapa a ciertos enfoques de la historiografía más reciente, que propone entender el franquismo como un régimen de control, construido por oposición a lo anterior, en el cual se quisieron eliminar los comportamientos no permitidos y, al mismo tiempo, fomentar otros de acuerdo a la norma definida ${ }^{44}$. Tanto la legislación como los procesos de depuración han demostrado que ya desde la guerra empezó a planearse el orden posconflicto. Como en todo régimen autoritario se hizo necesario establecer una definición oficial de cultura, sin posibilidad de múltiples interpretaciones. En los primeros compases de la dictadura, fueron los nacionalcatólicos integristas los que asumieron importantes puestos de poder, y en sus manos quedaron aspectos como la depuración de la ciencia y la cultura en el nuevo Estado, intentando aniquilar todo aquello relativo a la tradición liberal ${ }^{45}$. El nuevo orden académico no dependió exclusivamente de un proyecto de Estado cerrado, desde arriba, sino de los individuos que tuvieron el poder de tomar estas decisiones. La orientación de la cultura y la investigación españolas pasó a estar regida por el que iba a ser el "órgano supremo de la alta cultura española", el CSIC, en manos del Opus Dei.

El CSIC quiso plantear un modelo propio que, durante los cuarenta, sentó sus bases en el nacionalcatolicismo. La primera finalidad del CSIC fue la de fomentar, orientar y coordinar la investigación científica nacional ${ }^{46}$. Desde sus orígenes quiso marcar distancias con la JAE, y lo hizo reivindicando la creación de una cultura universal amparada en la hispanidad, planteada en claves muy distintas al periodo anterior, y vinculando "la producción científica al servicio de los intereses espirituales y materiales de la Patria" ${ }^{47}$. Los pilares de su proyecto fueron, por un lado, la subordinación de la ciencia al dogma católico y a los intereses del nuevo régimen, y por otro, un sentido de la Hispanidad que luego resultó fundamental en el desarrollo del

\footnotetext{
${ }^{44}$ Para una reflexión sobre el franquismo entendido como régimen de control, véase Alejandro PérezOlivares "El franquismo, ¿un régimen de control? Experiencias, dispositivos y espacios (desde el Madrid ocupado), Historia Social, no 97 (2020): 61-78.

45 Sara Prades Plaza, España y su Historia. La generación de 1948 (Valencia: Publicacions de la Universitat Jaume I, 2014), 29-30.

46 José María López, "El árbol de la ciencia El árbol de la ciencia nacionalcatólica: los orígenes del Consejo Superior de Investigaciones Científicas", Cuadernos de Historia Contemporánea, 38 (2016): $171-184$

${ }^{47}$ Ley de 24 de noviembre de 1939 creando el Consejo Superior de Investigaciones Científicas, Boletín Oficial del Estado, $\mathrm{n}^{\mathrm{o}} 332,28$ de noviembre de 1939, p. 6.669.
} 
americanismo académico. También se establecía, teóricamente, una vinculación muy cercana con la Universidad, reivindicando su autonomía y no queriendo mediatizar sus centros de actividad. En la práctica los investigadores del CSIC terminaron protagonizando un verdadero "asalto a las cátedras", haciendo uso de la doble competencia de Ibáñez Martín en el Ministerio y el Consejo ${ }^{48}$. El 10 de febrero de 1940 se publicó el Decreto que regulaba el reglamento y el funcionamiento del CSIC. Se establecían 6 patronatos que pretendían representar todos los valores de la Cultura. El responsable de las Humanidades fue el Patronato Marcelino Menéndez Pelayo, que contó entre sus institutos con el Jerónimo Zurita de Historia y el Gonzalo Fernández Oviedo de Historia Hispanoamericana.

En la inauguración del CSIC volvió a insistirse sobre los objetivos ideológicos del régimen, la necesidad de formar investigadores, el establecimiento de un sistema de becas e intercambio con centros extranjeros, y en establecer un contacto con las corporaciones legales para la realización de planes conjuntos de actividades ${ }^{49}$. La referencia al intercambio con centros extranjeros choca con el concepto de autarquía que, en ese momento, imperaba en el plano económico. Algunos autores han planteado la existencia de una "autarquía de la inteligencia"50 como expresión de la insostenibilidad del proyecto nacionalcatólico. En este caso, el aislacionismo académico no fue tanto una consecuencia exclusiva de la voluntad política, sino sobre todo de la represión de los propios docentes e investigadores. Quizás el concepto que más útil resulte para comprender la relación del Consejo con la comunidad internacional, al menos en la historiografía, sea el de "autarquía científica"51. Ésta no pretendió un aislamiento total frente a los planteamientos procedentes de otras escuelas europeas, sino de un claro intento por implantar un programa científico que rompiese con todo lo anterior: se pretendía que ese proyecto apelara a lo propio, a lo denominado en ese momento como "lo español", es decir, al nacionalcatolicismo. De esta manera se siguió

\footnotetext{
${ }^{48}$ Gonzalo Pasamar, "Oligarquías y clientelas en el mundo de la investigación científica; el Consejo Superior en la universidad de posguerra", en La universidad española bajo el régimen de Franco: Actas del Congreso celebrado en Zaragoza entre el 8 y 11 de noviembre de 1989 coord. por Juan José Carreras (Zaragoza: Institución Fernando el Católico, 1991), 335; Jaume Claret, El atroz desmoche..., 59.

${ }^{49}$ CSIC, Memoria de la Secretaría General, 1940-1941", p. V.

${ }^{50}$ Jaume Claret, El atroz desmoche..., 48-49.

${ }^{51}$ Para una conceptualización de este término vinculado a la Medicina, véase: José María López Sánchez, "La Medicina en la Universidad..., 317-320.
} 
haciendo uso de corrientes externas, pero sólo de aquellas consideradas como católicas, matizando dichas ideas.

En la historiografía, esta búsqueda de lo propio, de lo tradicional español, se llevó a cabo tomando como modelo a Menéndez Pelayo, personificando en él el ideal del nacionalismo español, el catolicismo ultraortodoxo y el conservadurismo militante. El proyecto se hizo insostenible en la década de los cincuenta, pero sí funcionó durante la posguerra. Todos estos procesos estuvieron comprendidos en el contexto de la victoria franquista y su esfuerzo por legitimar el nuevo régimen, esforzándose por crear una serie de apoyos sociales a través de un sistema de castigos y recompensas. Es aquí donde se insertan debates muy recientes sobre el concepto de "cultura de la Victoria", un conjunto de discursos y prácticas surgidos durante la Guerra Civil que explica la configuración del espacio público en claves de exclusión e integración al mismo tiempo $^{52}$. A través de la ideología, los valores y la cultura se pretendía legitimar el régimen, por lo que las diferentes instituciones no constituyeron elementos estáticos, sino que entraron dentro de ese juego de poderes en su lucha por asentar las bases de la dictadura. La dimensión nacionalista de la dictadura resulta fundamental para comprender la naturaleza del propio franquismo: esta identidad llegó a presidir gran parte de sus producciones ideológicas ${ }^{53}$.

La búsqueda de la tradición y la apuesta por la unión entre ciencia y fe se materializó también a nivel espacial y arquitectónico. La Colina de los Chopos también fue el escenario de un nuevo discurso científico. El CSIC ocupó los antiguos edificios de la JAE, pero fue una ocupación sobre todo funcional, ya que permitió una rápida puesta en marcha de la actividad científica. En una carta que Albareda hizo llegar a Ibáñez Martín le comunicó su intención de convertir los Altos del Hipódromo en una

\footnotetext{
${ }^{52}$ Claudio Hernández Burgos, "De la cultura de guerra..., 123-148. Una interpretación en clave punitiva, en Gutmaro Gómez y Alejandro Pérez-Olivares, "Las lógicas de la violencia en la guerra civil: balance y perspectivas historiográficas", Studia Historica. Historia Contemporánea, no 32 (2014); 251-262.

${ }^{53}$ Ismael Saz, "Las culturas de los nacionalismos franquistas", Ayer, no 71 (3/2008): 153-174; Sara Prades Plaza, "Discursos históricos e identidad nacional: la Historia de España del nacionalcatolicismo franquista", en La nación de los españoles. Discursos y prácticas del nacionalismo español en la época contemporánea ed. por Ismael Saz y Ferrán Archilés (Valencia, Publicaciones de la Universitat de València, 2012), 55-79.
} 
verdadera ciudad de $\operatorname{Dios}^{54}$. La vinculación entre ciencia y religión no debía limitarse a la práctica científica, sino que podía materializarse en su propio campus. La labor arquitectónica y urbanística del nuevo régimen se habían convertido también en una actividad política supeditada a las necesidades del Nuevo Estado. Simbolizaba una forma de erigir el continente material en el que se pudieran encarnar los valores eternos del alma de España ${ }^{55}$. Los encargados de llevar a cabo este proyecto en 1942 fueron Isidoro Zorzano, Fernández Vallespín y Miguel Fisac, todos miembros del Opus Dei. Este último fue el encargado de convertir el antiguo auditorio y biblioteca de la Residencia de Estudiantes y del Instituto-Escuela, en una iglesia puesta bajo la advocación del Espíritu Santo. Esa transformación era el "símbolo de que toda la empresa investigadora española se inspira en el afán cristiano de servir a Dios y con Él a la verdad y el bien" ${ }^{, 56}$. Fisac quiso encontrar el equilibrio entre tradición y modernidad, adaptando la antigua construcción de Arniches y Domínguez a sus intereses, sin tener que echarlo abajo. De esta manera, el claustro que organizaba las salas de bibliotecas y aulas en el antiguo edificio pudo mantenerse intacto, una solución acorde con los presupuestos tradicionalistas del novecentismo italiano ${ }^{57}$. La nueva iglesia ejemplificaba cómo lo moderno y lo tradicional podían reunirse, y de cómo esto podía extenderse a la nueva ciencia española ${ }^{58}$. Se pretendió resaltar el carácter monumental del conjunto como forma de hacer patente "el papel directivo que la investigación ha de tener en los futuros destinos de los pueblos" $" 59$.

Una vez conformados los mimbres internos del proyecto, se hizo necesario cuidar la imagen a proyectar de cara al exterior. El CSIC ayudó a construir una

\footnotetext{
${ }^{54}$ La noticia de esta correspondencia está recogida en Lino Camprubí, Los ingenieros de Franco. Ciencia, catolicismo y Guerra Fría en el Estado franquista (Barcelona: Crítica, 2017), 44.

${ }^{55}$ Zira BOX, "El cuerpo de la nación..., 151-181.

${ }^{56}$ Miguel Fisac, "La Iglesia del Espíritu Santo en la calle de Serrano”, Gran Madrid, no 5 (1949): 10. Citado en Ramón Vicente Díaz del Campo y Martín Mantero, "El conjunto del CSIC en Madrid (19391949). La creación de la ciudad de Dios y la Ciencia", en Memoria e identidades. VII Congreso da Asociación de Historia Contemporánea coord. por Justo Beramendi y María Xesús Baz (Santiago de Compostela, Universidad de Santiago de Compostela, 2004), s/n.

57 Salvador Guerrero, "El conjunto urbano del CSIC en Madrid: retórica y experimentalismo en la arquitectura española del primer franquismo", en Tiempos de investigación: JAE-CSIC, cien años de ciencia en España coord. por Miguel Ángel PUIG SAMPER (Madrid, CSIC, 2007), 285-292.

${ }^{58}$ Lino Camprubí, Los ingenieros..., 45-47.

59 José Zamón Aznar, “Un conjunto monumental”, $A B C$, 12 de noviembre de 1946.
} 
dimensión pública de la cultura franquista mediante actividades destinadas a un público más amplio. La comunidad historiográfica fue, en general, bastante hermética. Sin embargo, hubo ciertos momentos en que se abrió una colaboración en el plano político, "una intersección entre la Historia y la política; entre los espacios corporativos (y semiprivados) de la Historia y los públicos; entre los ejercicios eruditos y la propaganda $\mathrm{y}$, por último, entre el pasado y sus detentadores en el presente" ${ }^{\prime 60}$. Esto fue posible a través de ciertas conmemoraciones donde se combinaron el dominio del espacio oficial y el público. Éstas facilitaron no solo poner en escena la reivindicación de un pasado concreto, sino también la construcción de un presente basado en los valores del Nuevo Estado.

En el caso del Consejo, durante estos primeros años la irrupción en el espacio público no se llevó a cabo, en general, de forma directa. Fueron sus investigadores quienes, desde su faceta política en otros organismos, desarrollaron distintos usos públicos de la historia. Esta duplicidad de cargos en investigadores de muy distintos niveles es una muestra de las redes que se fueron tejiendo entre el CSIC y otras esferas de poder político o académico, y explican la relevancia del organismo durante este periodo. Así, Fray Justo Pérez de Urbel, miembro del Instituto Jerónimo Zurita, participó en la organización del Milenario de Castilla, celebrado en 1943. Éste fue colaborador del Instituto desde 1940 hasta 1949, momento en que pasó a la Escuela de Estudios Medievales, también del $\mathrm{CSIC}^{61}$. A su vez, fue consejero nacional del Movimiento y primer abad del monasterio del Valle de los Caídos ${ }^{62}$. Constituyó uno de los casos más claros de una carrera construida con ayuda del poder académico: en tan solo cinco años obtuvo su bachillerato, la licenciatura, la tesis doctoral y, finalmente, la cátedra universitaria ${ }^{63}$.

\footnotetext{
${ }^{60}$ Gustavo Alares, "La conmemoración del Milenario de Castilla en 1943. Historia y espectáculo en la España franquista", Revista Jerónimo Zurita, nº 86 (2011): 86-87.

${ }^{61}$ Nóminas del Instituto Jerónimo Zurita. AGA. Educación. Fondo CSIC. LIBROS 288 TOP. 32/00.20100.406 y 448 TOP. 32/00.201-00.406, respectivamente.

${ }^{62}$ Ignacio Peiró y Gonzalo Pasamar, Diccionario Akal de historiadores españoles contemporáneos (Madrid: Akal, 2002), 485-486.

${ }^{63}$ Ruben Pallol, "La Historia, la Historia del Arte, la Paleografía y la Geografía en la universidad nacionalcatólica", en La universidad nacionalcatólica, ed. por Luis Enrique Otero (Madrid: Dyckinson, 2014), 639 .
} 
Pérez de Urbel fue miembro destacado de la Comisión Organizadora del Milenario, participando en sus actos y encargándose de la propaganda para la prensa. En la celebración se aunaron una identidad histórica colectica, la retórica y estética franquistas y la cultura conmemorativa del régimen ${ }^{64}$. Burgos, que había sido capital de la "Cruzada" durante la guerra, se convirtió en un gran escenario que glorificaba a Franco y al conflicto como origen de la dictadura, aunque a lo largo de la década de los cuarenta cualquier espacio podía ser propicio para convertirse en escenario de la reespañolización y recatolización a pie de calle. La cultura fue un arma para legitimar ese régimen, y de ahí la importancia de dotarla de una dimensión pública. La celebración del Milenario tuvo un origen local, cuando un grupo de Falange decidió retomar la idea de exaltar a Castilla que ya era propia de esa organización. A lo largo del proceso organizativo sufrió un proceso de faszistización a partir del cual se elevó a rango nacional, hasta que terminó participando la Secretaría General del Movimiento y contando con la aquiescencia de la Jefatura del Estado. A través de su participación, Pérez de Urbel pudo difundir el nacionalismo de falange y reivindicar una imagen de Castilla como heroína de un proceso histórico guiado por la unidad de destino en lo universal $^{65}$.

El CSIC sí tuvo intención de proyectarse hacia el exterior mediante otra actividad destacada, la de sus revistas ${ }^{66}$. Desde la puesta en marcha del CSIC, la difusión de su creciente actividad se reveló como un objetivo prioritario: "S.E. el Caudillo ha mostrado repetidas veces el deseo de que la labor fecunda y callada de los sabios e investigadores sea conocida entre el gran público, y por ello me permito rogarle a Vd. encargue a alguno de los redactores escriba crónicas hablando de estos asuntos"67. En este oficio, de finales de 1940, se observa la intención de Alfredo Sánchez Bella, Vicesecretario del Consejo y encargado de la Oficina de Publicaciones en esos primeros momentos, de dar a conocer las publicaciones periódicas del CSIC en medios externos.

\footnotetext{
${ }^{64}$ Gustavo Alares, Politicas del pasado en la España franquista (1939-1964). Historia, nacionalismo y dictadura (Madrid: Marcial Pons, 2017), 37-113.

${ }^{65}$ Gustavo Alares, "La conmemoración del Milenario, 160.

${ }^{66}$ Fernando García Naharro, "El papel de la Ciencia. Publicaciones científicas y técnicas durante el franquismo (1939-1966)" (Tesis doctoral, Universidad Complutense de Madrid, 2016).

${ }^{67}$ Oficio de Alfredo Sánchez Bella sin destinatario ni fecha. AGA. Educación. Fondo CSIC. Caja 31/8534. Carpeta Secretaría. Por los datos que aparecen en el documento, éste se escribió hacia finales de 1940.
} 
Este interés no nacía exclusivamente desde una preocupación de los propios investigadores por enriquecer la sociedad de la que formaban parte, sino que venía impuesto desde arriba, como forma de legitimación y justificación del régimen.

En la construcción del nuevo Estado se había escogido al Consejo como "la máxima jerarquía en la vida cultural del país" ${ }^{68}$. Sin embargo, es necesario plantearse si realmente terminó funcionando como "brazo armado cultural" del franquismo, si todos sus investigadores se sintieron realmente identificados con estos discursos o la práctica de su actividad terminó adoptando sus propias lógicas. En su relación con la cultura, el objetivo del CSIC fue optar por una suerte de aculturación por oposición al periodo anterior: la construcción de un orden académico propio a través de la destrucción de ese pasado $^{69}$. Divergieron, sin embargo, la teoría y la práctica: optaron por destruir lo anterior, pero tuvieron que servirse de ello para su supervivencia. Esto es relevante porque no solo supuso continuidades materiales, sino también de algunas prácticas dentro de la profesión. En un momento en que se estaban recibiendo fuertes críticas desde el exilio y la comunidad internacional miraba a España ${ }^{70}$, la producción científica pretendió constituir la muestra de que el proyecto sí era capaz de dar sus frutos, configurándose como la cara visible de las actividades llevadas a cabo.

Ibáñez Martín y Albareda encargaron la organización del primer servicio de publicaciones a Alfredo Sánchez Bella. Su primera medida fue liquidar la incautación de las publicaciones de la JAE. El 15 de julio de 1940 se reunió con Julio Palacios, Vicepresidente del Instituto de España, Antonio de la Torre, vocal del Patronato Marcelino Menéndez Pelayo y vicedirector del Jerónimo Zurita, y Vicente Castañeda, Secretario de Publicaciones del Instituto de España, para formalizarlo. Se le entregaron las publicaciones que la Junta tenía en el edificio de Medinaceli (antiguo CEH y ahora edificio del Consejo), así como un catálogo de las publicaciones editadas por ésta y una

\footnotetext{
${ }^{68}$ Orden de 8 de marzo de 1940 disponiendo que el CSIC gozará de la máxima jerarquía en la vida cultural del país, Boletín Oficial del Estado, nº 78, 18 de marzo de 1940, p. 1.897.

${ }^{69}$ Para diferentes modos de abordar la construcción de un nuevo Estado, véase: Eric Carlton, Occupation. The Policies..., 43-54.

${ }^{70}$ José María López Sánchez, Los refugios de la derrota. El exilio cientifico e intelectual republicano de 1939 (Madrid: Consejo Superior de Investigaciones Científicas / Los Libros de la Catarata, 2013).
} 
carpeta con antecedentes y notas de las publicaciones en trámite ${ }^{71}$. Esto hizo posible el sostenimiento de las primeras actividades científicas del CSIC, ya que los Institutos aprovecharon para continuar algunas de las revistas científicas creadas por la Junta y que ya contaban con una consolidada trayectoria y prestigio dentro de sus disciplinas. Lo mismo ocurrió con algunos proyectos editoriales en marcha, donde en algunos casos llegó a reclamarse material a algunos intelectuales que estaban en el exilio, reivindicándolo como propio $^{72}$. De esta forma, mientras se desacreditaba el pasado anterior, sí parecía posible recurrir a él, siempre y cuando se desposeyera de significado $\mathrm{o}$, en la práctica, se desvinculase de él nominalmente a quienes no compartían el nuevo ideario.

Todo esto explica que, habiéndose creado el organismo en noviembre de 1939 y habiéndose conformado algunos de sus institutos durante los primeros meses de 1940, ya a finales de ese mismo se hubiesen publicado trece revistas y estuviesen en prensa quince más $^{73}$. La antigua revista Tierra Firme, creada en 1935 por la Sección americanista del $\mathrm{CEH}$, fue considerada por Antonio Ballesteros Beretta y Ciriaco Pérez Bustamante, del Instituto Gonzalo Fernández de Oviedo, “de imprescindible continuación, base del intercambio de todas las revistas que aún en gran número siguen llegando al Instituto y obra que no puede interrumpir porque sería dar sensación de marasmo y decadencia que hay que evitar" ${ }^{74}$. Se impuso, eso sí, un cambio de cabecera, y pasó a llamarse Revista de Indias. En consonancia con la prisa por demostrar la existencia de actividad científica, su primer número apareció en agosto de 1940, “disponiendo de abundante material de propaganda, por sus relaciones y ficheros especializados, tiene en proyecto una magna difusión de un prospecto de propaganda

\footnotetext{
71 Archivo General de la Administración (AGA). Educación. Fondo CSIC. Caja 31/8534. Carpeta Secretaría

72 Alba Fernández Gallego, "La construcción..., 257-280.,

73 "Relación de las Revistas y Boletines que se publicaban con anterioridad al Glorioso Movimiento Nacional por los Centros hoy dependientes del Consejo Superior de Investigaciones Científicas". Archivo General de la Administración (AGA). Educación. Fondo CSIC. Caja 31/8536. Carpeta "Ministerio. Varios"

${ }^{74}$ Informe «Labor a desarrollar por el Instituto Fernández de Oviedo» de Ciriaco Pérez Bustamante, con el $\mathrm{V}^{\circ} \mathrm{B}^{\mathrm{o}}$ de Antonio Ballesteros Beretta, 10 mayo 1940. AGA. Educación. Fondo CSIC. Caja 31/8531. Carpeta Instituto Gonzalo Fernández de Oviedo
} 
que a tal fin ha mandado confeccionar" ${ }^{75}$. El término empleado, "propaganda", no pasa desapercibido: el objetivo no era solo volver a poner en marcha la investigación, sino que era fundamental que esto fuese acompañado de una labor de difusión de las nuevas líneas impulsadas. De hecho, en la correspondencia interna de inicios de 1940, a la hora de proponer un equipo de redacción, éste se propuso para la revista Tierra Firme: todavía no se referían a ella como Revista de Indias ${ }^{76}$. La publicación había tenido muy poco recorrido, ya que salió a la luz en 1935 y fue una revista anual de cuatro números dedicada no sólo a temas hispanoamericanos, sino también a otros de actualidad sobre diferentes materias ${ }^{77}$.

También se fueron creando otras nuevas, como forma de completar todas las disciplinas con revistas de nuevo cuño que diesen la imagen de una labor incesante de investigación. La continuación de estas revistas y el aluvión de otras nuevas nos muestra dos aspectos muy relevantes en la constitución del CSIC y su práctica científica. En primer lugar, la importancia de ocupar los espacios de poder académico y de producción del conocimiento en la reconfiguración del mundo académico. A nivel nacional, el CSIC sí había conseguido este control en el terreno legislativo y material. Sin embargo, poner en práctica sus políticas científicas y conseguir resultados satisfactorios de cara a una comunidad internacional en la que ya se habían superado los planteamientos científicos del nacionalcatolicismo, iba a costar más. Por ello, para buscar su reconocimiento, se hizo uso de los medios de la JAE sin perjuicio de su procedencia.

En segundo lugar, el devenir de las publicaciones periódicas muestra la capacidad de agencia que tenían los historiadores del Consejo. Muchos de ellos habían conseguido sus puestos recurriendo a un capital académico entendido como la apelación más o menos directa al nacionalcatolicismo. Otros, sin embargo, se sirvieron del mismo capital, entendido como la inserción en redes intelectuales ${ }^{78}$. A pesar de ello, una vez

\footnotetext{
${ }^{75}$ Oficio de Manuel Ballesteros, Secretario en funciones del Instituto Gonzalo Fernández de Oviedo, al Secretario General del CSIC, 19 agosto 1940. AGA. Educación. Fondo CSIC. Caja 31/8531. Carpeta Instituto Gonzalo Fernández de Oviedo

${ }^{76}$ Carta de Antonio Ballesteros, director del Instituto, al Presidente del Patronato Menéndez Pelayo, mayo de 1940. AGA. Educación. Fondo CSIC. Caja 31/8531. Carpeta Instituto Gonzalo Fernández de Oviedo.

${ }^{77}$ Sobre la revista Tierra Firme véase Salvador Bernabéu y Consuelo Naranjo, Tierra Firme (Madrid: Residencia de Estudiantes / Consejo Superior de Investigaciones Científicas, 2007).

${ }^{78}$ Entendemos por capital académico una expresión clave del nuevo orden que encarnaba el CSIC. Esta noción entiende que el nacionalcatolicismo fue una suerte de «capital cultural», una tradición intelectual
} 
puesta en marcha la estructura, cada Instituto tuvo cierta autonomía para desarrollar su trabajo. Solo así se explica la continuación de unas publicaciones en las que habían participado intelectuales de gran renombre que se encontraban ahora excluidos de la nueva comunidad académica. Era la forma de retener el capital científico que proporcionaban y afianzar el proyecto nacionalcatólico mediante la retención de cotas de poder frente a otros sectores católicos y Falange, lo que se concretó en los crudos enfrentamientos por las cátedras. Más allá del alcance real que pudiesen tener las revistas de cara a un público amplio, fueron concebidas como una plataforma de difusión para sus discursos. Además, fueron un medio de intercambio bibliográfico, con el que hacerse con las investigaciones más novedosas, a la vez que asegurarse un sitio en las bibliotecas de esos centros externos. Acercarse a su contenido permitirá traspasar la imagen proyectada de la misión que debían llevar a cabo y descender a la realidad de la práctica historiográfica.

\section{HISPANIA Y REVISTA DE INDIAS: LA PRÁCTICA HISTIOGRÁFICA SOBRE EL PAPEL}

El análisis de las revistas de historia del Consejo ofrece algunas claves sobre la práctica historiográfica llevada a cabo en este periodo, así como de sus rupturas y continuidades. Analizar los periodos o temáticas que más se transitaron puede proporcionar claves sobre el reparto de poder de las distintas escuelas. Así se puede acceder a las redes intelectuales que fueron construyéndose y a la conformación de la propia arquitectura institucional: si las revistas eran altavoces de los institutos o fomentaban el intercambio intelectual, su grado de difusión, etc. Se podrá ver cómo se definió la historiografía como práctica, las relaciones que hubo entre el saber historiográfico y las estructuras de poder. Es importante conocer si los investigadores tenían alguna capacidad de agencia frente al discurso público, tanto estatal como institucional. En este caso se van a analizar dos de las revistas de historia más relevantes, durante estos primeros años de vida de la institución: Hispania, de historia

\footnotetext{
inapelable en la posguerra franquista, que ayudó a promocionar a muchos investigadores. Pero también reivindicamos la importancia de ciertos aspectos de la práctica historiográfica, alejados de los discursos oficiales, como la pertenencia a escuelas historiográficas o la construcción de redes. Es decir, lo que Bourdieu entiende como «capital social». Véase Pierre Bourdieu, Homo academicus (México: Siglo XXI Editores, 2009); Pierre Bourdieu, Capital cultural, escuela y espacio social (Madrid: Siglo XXI, 1997).
} 
general y dependiente del Instituto Jerónimo Zurita, y Revista de Indias, de historia hispanoamericana y dependiente del Instituto Gonzalo Fernández de Oviedo ${ }^{79}$.

Una mirada más detenida a Hispania, de nuevo cuño, nos sugiere que sí pudo tener inspiración en el periodo anterior: el Anuario de Historia del Derecho. En el CEH las investigaciones históricas se habían desarrollado sobre todo bajo el amparo de este anuario, ya que la historia del derecho español estuvo muy vinculada con la historia medieval y sus instituciones. La publicación del CEH contaba con cuatro partes: una sobre temas de historia del derecho español, hispanoamericano y musulmán; una segunda sobre documentos relevantes para la historia del Derecho; otra de bibliografía donde se recogieron recensiones de aquellas obras de interés para la historia del Derecho; y una última de "Varia" donde tuvieron cabida noticias relacionadas con la actividad de la sección, la organización de congresos nacionales o internacionales y cualquier acontecimiento de relevancia en materia de historia del Derecho. El CSIC creó su propio Instituto dedicado al Derecho, donde se incluyó una sección de Historia del Derecho. Parece ser que fue Hispania, desde el Jerónimo Zurita, quien tomó el relevo del Anuario, ya que, aunque su estructura no es constante, los primeros años contó también con secciones parecidas: una sobre investigaciones historiográficas; una de "varia", para investigaciones más breves; notas bibliográficas; otra de "información" con noticias internas o de congresos; y una necrológica, intermitente. La de Bibliografía de Ciencias Históricas, a cargo de Ramón Paz y Remolar, llegó a tener tanta importancia y extensión que se aconsejó segregarla y editarla por separado ${ }^{80}$. Los periodos históricos abordados en Hispania desde 1940 hasta 1944 reflejan la configuración interna del Instituto:

\footnotetext{
${ }^{79}$ Para este objetivo resulta de gran interés también la revista Arbor, que no se analiza aquí por empezar su publicación de forma posterior, en 1946, y por contar ya con interesantes estudios. Véase: Sara Prades, "Escribir la historia para definir la nación. La historia de España en Arbor, 1944-1956", Ayer, no 66 (2007): 177-200; Gonzalo Pasamar, "Cultura católica y elitismo social: la función política de Arbor en la posguerra española", en Arbor. Ciencia, pensamiento y cultura, 479-480 (1985): 17-38.

${ }^{80}$ Memoria de los 10 primeros años del Instituto Jerónimo Zurita, sin fecha. AGA. Educación. Fondo CSIC. Caja 31/9322. Carpeta Instituto Jerónimo Zurita
} 


\section{Gráfico 1. Revista Hispania, 1940-1944. Periodos abordados}

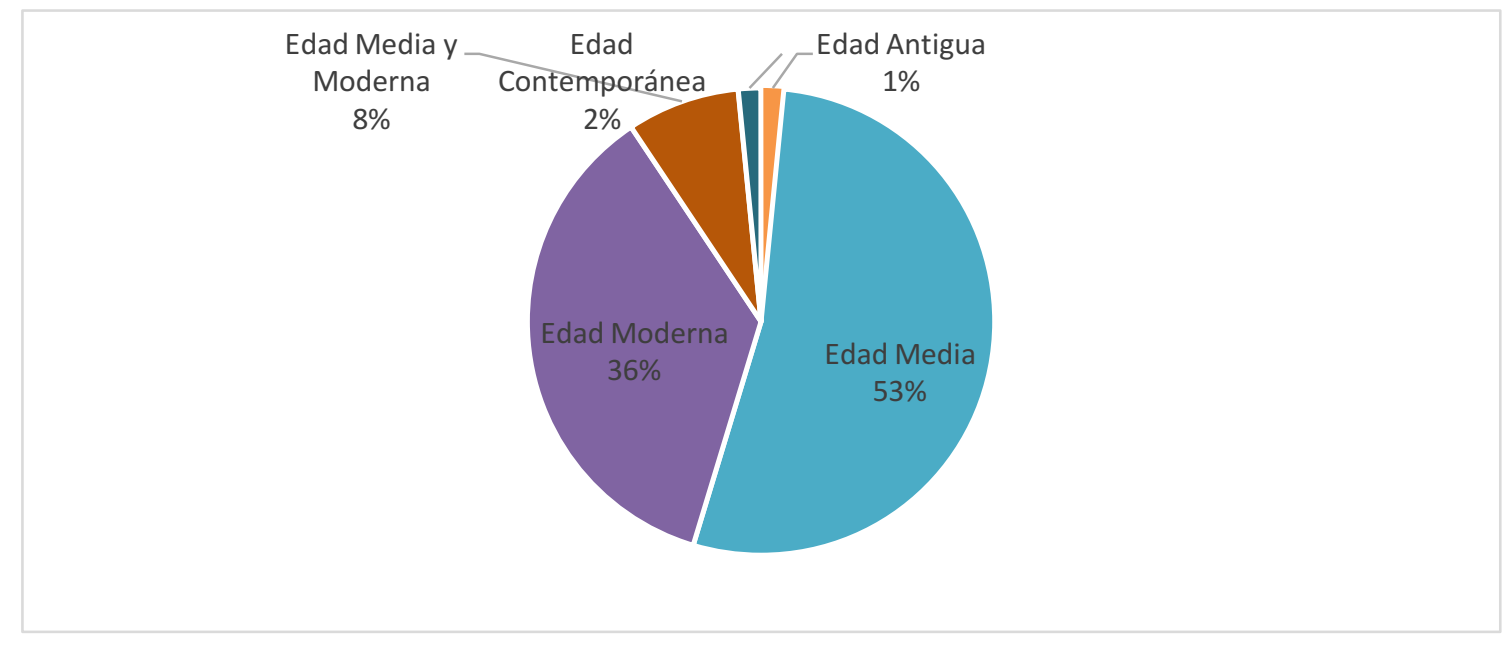

Fuente: números I-XVII de la revista Hispania. Elaboración propia

El "gráfico 1" muestra cómo más de la mitad de las publicaciones estuvieron dedicadas a la Edad Media, seguidos por un importante número de estudios dedicados a la Edad Moderna. Cinco de ellos (el 2\%) proponían estudios de más largo recorrido, desarrollándose en ambos periodos, aunque si observamos más detenidamente en realidad cuatro de ellos son el mismo dividido en cinco números: "De la Edad Media a la Moderna. El Cantábrico y el Estrecho de Gibraltar en la historia política española”, de Carmelo Viñas Mey, Colaborador del Zurita y catedrático en la Universidad Central. En sus inicios, el Jerónimo Zurita dividió sus Secciones en la de Historia Moderna, a cargo Pío Zabala, y la de Historia Medieval, dirigida por Antonio de la Torre. Este último consiguió trasladarse a Madrid en 1942 para hacerse cargo de la cátedra de Historia de España Medieval ${ }^{81}$. Se creyó oportuno mantener esta doble vertiente también en la revista $^{82}$. El primero fue el director de la revista y el segundo, el subdirector ${ }^{83}$. Esto explica la alta presencia de estos periodos en la revista. En cuanto a la Historia Contemporánea, su escasa presencia se explica porque fue controlada casi en su

\footnotetext{
${ }^{81}$ Ruben Pallol, "La Historia..., 540.

${ }^{82}$ Carta al Secretario del Consejo, 20 de diciembre de 1940. AGA. Educación. Fondo CSIC. Caja 31/8531. Carpeta Instituto Jerónimo Zurita.

${ }^{83}$ Informe de la estructura del Instituto Jerónimo Zurita, sin fecha. AGA. Educación. Fondo CSIC. Caja 31/8543. Carpeta Escuela de Estudios Medievales. El documento hace referencia a las actividades hasta 1944, por lo que se supone de ese periodo.
} 
totalidad por el Instituto de Estudios Políticos durante los años cuarenta, quien la utilizó para fines propagandísticos ${ }^{84}$.

Además de contar con más trabajos medievalistas, un número importante de los estudios modernistas que se publicaron procedían de investigadores externos al Consejo. Esto parece indicar que se siguió la tradición medievalista de la JAE, que respondía a la de la propia evolución historiográfica. Así, al gusto por la recuperación de ese pasado nacional, se unió la necesidad de recurrir a las dinámicas previas para poder sacar adelante una actividad incesante. Si durante el siglo XIX se había idealizado lo medieval como factor de legitimación de los nuevos estados de régimen político liberal, la nación, ahora entendida como ente inmutable e intemporal, se identificó con una forma política concreta, la del estado-nación, y la historia se interpretaba teleológicamente como el proceso ineludible de ascenso de éste ${ }^{85}$. El grupo de intelectuales nacidos en torno a la ILE y a la crisis del 98 siguieron un camino parecido, tratando de comprender y definir una esencia o personalidad de la nación española. Para ellos, Castilla adquirió una personalidad histórica propia, era el centro, la personificación del estilo del nacionalismo liberal ${ }^{86}$. Frente a ello, Menéndez Pelayo destacó la conversión de Recaredo, los Reyes Católicos, el Concilio de Trento o la Guerra de Independencia, como momentos álgidos de la creación de una nacional española.

Este impulso del medievalismo hizo que se buscase la colaboración entre distintas materias en distintas localidades para poder conocer con mayor profundidad ese periodo. Los grandes impulsores del proyecto fueron Alfonso García Gallo, desde su cátedra de Historia del derecho español en Valencia; José María Lacarra a través del Centro de Estudios Medievales de Aragón y de su cátedra de Historia Medieval en la Universidad de Zaragoza; y la sección de Barcelona del Instituto, estrechamente ligada al Archivo de la Corona de Aragón, con Fernando Valls Taberner y Ernesto Martínez

\footnotetext{
${ }^{84}$ Gonzalo Pasamar e Ignacio Peiró, Historiografía y práctica social en España (Zaragoza: Universidad de Zaragoza, 1987); Miquel Marín Gelabert, "Revisionismo de Estado..., 368.

${ }^{85}$ Julio Escalona, Cristina Jular e Isabel Alfonso, "El medievalismo, lo medieval y el CSIC en el primer franquismo", en El franquismo y la apropiación del pasado. El uso de la historia, de la arqueología y de la historia del arte para la legitimación de la dictadura ed. por Francisco J. Moreno Martín (Madrid: Editorial Pablo Iglesias, 2016), 159-188.

${ }^{86}$ Javier Varela, La novela de España. Los intelectuales y el problema español (Madrid: Taurus, 1999).
} 
«Una ciencia para la verdad y para el bien ». Los historiadores del Consejo Superior de Investigaciones Cientificas y la institucionalización del orden académico franquista

Ferrando sucesivamente a la cabeza ${ }^{87}$. La primera década de su existencia estuvo marcada por la investigación medieval y especialmente por la época de los Reyes Católicos, acorde con el discurso nacionalcatólico que pretendía imponerse. Muestra de ello es que uno de los primeros trabajos que se quiso impulsar utilizando las fuentes del Archivo de la Corona de Aragón fue una Correspondencia diplomática de Fernando el Católico $^{88}$. La atribución del surgimiento de la nacionalidad española a los Reyes Católicos durante la Restauración, se traducía ahora a una publicística biográfica y apologética de su reinado. Se quiso presentar la Historia como una lucha constante entre la civilización cristiana y todas las demás fuerzas que conspiraban contra ella. A este tema se dedicó, casi en exclusivo en la revista, el propio Antonio de la Torre, quien escribió acerca de Cisneros, en su papel de confesor de Isabel la Católica ${ }^{89}$, sobre un médico de los Reyes Católicos y sobre las joyas de Boabdil. También Luis Batlle y Prats abordó esta temática en su vertiente localista, con el viaje de los reyes a Gerona ${ }^{90}$.

Se privilegió el estudio de la Reconquista y los momentos de grandes empresas religiosas, algo que tiene una fuerte presencia en la revista. Del aspecto religioso se encargaron durante esos años Fray Justo Pérez de Urbel, Emilio Sáez, Julio González, José Rius Sierra o Ernesto Martínez, Luis Sala Balust y A. Xavier Garrigós. Estos dos últimos no pertenecían al Consejo, sino que colaboraron con él desde la Universidad Pontificia de Salamanca, una institución católica creada en 1940. Así, las primeras redes con otros centros buscaron la proximidad ideológica y nacional, más que un prestigio científico consolidado. El resto eran desde becarios hasta colaboradores o jefes de sección del Zurita o la Escuela de Estudios Medievales de Barcelona, lo que da una visión de una fuerte organización alrededor de esta temática. La parte de la Reconquista la trataron Eduardo Ibarra Rodríguez, Julio González, el abad de Silos (investigador independiente que abordó tanto el periodo medieval como el contemporáneo) y Quiteria

\footnotetext{
${ }^{87}$ Gonzalo Pasamar, Historiografía e ideología en la postguerra española: la ruptura de la tradición liberal (Zaragoza: Prensas Universitarias, 1991), 149.

88 “Consejo Superior de Investigaciones Científicas. Memoria de la Secretaría General, 1940-1941”, p. 153.

${ }^{89}$ Antonio de la Torre, "Cisneros, confesor de la Reina", Hispania. Revista española de Historia, $\mathrm{n}^{\circ} 1$ (1940): 43-51.

${ }^{90}$ Este interés por los estudios locales llevó más adelante a la creación del Instituto Quadrado. Véase: Miquel Marín Gelabert, Los historiadores españoles en el franquismo, 1948-1975. La historia local al servicio de la patria (Zaragoza: Prensas Universitarias : Institución Fernando el Católico (CSIC), 2005).
} 
Fernández Arroyo, consolidándose como un tema recurrente. Ésta fue la única mujer que publicó en la revista durante sus primeros años, como becaria del Jerónimo Zurita. Los temas abordados reflejan un interés por la Corona de Aragón, algo que puede tener dos explicaciones: el fuerte núcleo de medievalistas que se formó en torno a las cátedras de Zaragoza y Barcelona, con el archivo de la Corona como centro; y una idea de nación española forjada de forma destacada en Aragón ${ }^{91}$. La mayoría de los trabajos seguían una metodología tradicional, realizando una historia política dedicada a las grandes figuras del pasado. A estos estudios le seguía una incesante publicación de fuentes y transcripciones de documentos, así como glosarios y códices.

En el terreno modernista, se suelen destacar los siglos XVI y XVII como momentos privilegiados, al ser considerados el momento álgido del imperio español. Esto se reflejó en las oposiciones para las cátedras de "Historia de España Moderna y Contemporánea" en las Facultades de Sevilla y Santiago, a las que se presentaron Luis de Sosa, Joaquín Pérez Villanueva y Antonio Rumeu de Armas, todos miembros del Instituto. En su memoria a cátedra, Luis de Sosa defendió la Edad Moderna como "la etapa en que frente a una desorientación universal, España impone un sentido católico e imperial a la Humanidad, encaja un modo de vivir y crea, como superación de la raza la Hispanidad, frente a la conjura de los mediocres" ${ }^{\prime 92}$. Es curioso que ninguno de ellos volcase esos intereses en la revista de su Instituto: quizás no lo necesitaban, ya que los tres ocupaban cargos importantes en el CSIC y los tres consiguieron sus cátedras universitarias en 1940, los dos primeros, y 1943. Pero, sobre todo, lo que ocurrió es que los estudios modernistas habían estado más vinculados al americanismo desarrollado durante la Segunda República. Quizás por ello en la revista hay varios artículos de Vicente Rodríguez Casado, integrado el instituto dedicado a los estudios hispanoamericanos y no en el Zurita. Siguiendo esta dinámica anterior a la guerra, la década de los cuarenta comenzó con una ausencia de tradición modernista que marcó el proceso de institucionalización de la historia moderna en la Universidad. La práctica histórica del modernismo siguió la de la actividad medievalista: priorizó los estudios políticos y diplomáticos, se enfrentó a las fuentes con parecidas herramientas

\footnotetext{
${ }^{91}$ Informe sobre la Sección de Estudios de Historia de la Edad Media de la Corona de Aragón, sin fecha. AGA. Educación. Fondo CSIC. Caja 8540. Carpeta Jerónimo Zurita 1943.

92 Rubén Pallol, “La Historia..., 565. 
metodológicas, no delimitó su campo de saber y, además, estuvo carentes de circuitos profesionales $^{93}$.

A pesar de esta visión, en las publicaciones de la revista despertaron el mismo interés los siglos XVII y XVIII, incluso este último tuvo una publicación más. Lo que sí es cierto es que, de las 23 publicaciones de la revista que hubo sobre Historia Moderna en esos años, más de la mitad, 14, se centraron en el siglo XVI. Esos trabajos se vieron enriquecidos por los proyectos realizados en el Archivo de Simancas, que desempeñó un papel clave, hasta tal punto que el Jefe de Sección llegó a denominarlo "el primer Archivo de la Historia Moderna de Europa"94. En las Memorias de 1943 se hablaba ya de la ambición de preparar una gran historia de los reinados de los Reyes Católicos, Carlos V y Felipe II, y poco después se habló de la redacción de una "gran Historia del Imperio español"95. Desde 1940 hasta 1944, Alfredo Sánchez Bella fue el único que trató la figura de Carlos V, desde su relación con la Compañía de Jesús. Felipe II sí despertó un mayor interés, aunque desde investigadores externos al instituto (con la excepción de Miguel Lasso de la Vega). Todo ello parece indicar que las propuestas que lanzaba el nacionacatolicismo en lo relativo al pasado nacional no siempre tuvieron su respuesta en la práctica cotidiana de la profesión, al menos en algunos de sus órganos de expresión. En su revista Hispania, el Zurita fue mucho más comedido en sus discursos.

Lo contrario sucedió con el Instituto Fernández de Oviedo y el americanismo, donde el discurso impulsado desde la Revista de Indias fue mucho más contundente:

Ha creado el «Instituto Gonzalo Fernández de Oviedo» para cumplir la misión que a España incumbe en los estudios de historia americana. Los designios de Dios señalaron el destino de España con la gloria del descubrimiento y la civilización del Nuevo Mundo, asignándole una trascendental personalidad histórica que debe asumir siempre, y más aún en esta hora nuestra de revisiones y también de rectificaciones [...] Pero como los pueblos hispánicos son un desdoblamiento de España en el mundo, resulta evidente que España no puede estar ausente de sí misma [...] En estos momentos

\footnotetext{
93 Eduardo Acerete, "Formaré junto a mis compañeros. Las obras militantes del catedrático Carlos E. Corona Baratech”, Jerónimo Zurita. Revista de Historia, no 93 (2018): 209-232.

${ }^{94}$ Carta del Jefe de Sección al Secretario del Consejo, 1 de diciembre de 1946. AGA. Educación. Fondo CSIC. Caja 8556. Carpeta Patronato Menéndez Pelayo 1947.

95 “Consejo Superior de Investigaciones Científicas. Memoria de la Secretaría General, 1944”, p. 147.
} 
convulsivos en que se agita el mundo, cuando elementos de disolución quisieran arruinar la obra del pasado, las entidades históricas, firmes, nobles y enteras, han de sostener la responsabilidad que sobre ellas gravita, para salvar lo que representa valor en la vida del espíritu. Y uno de estos grandes valores fue y es la Hispanidad, [...] En la Hispanidad existe la unidad esencial de creencias, de idioma y de costumbres. España en Europa e Hispano-América en el Nuevo Mundo son un conjunto positivo, un núcleo histórico de cultura y civilización, una realidad incontrovertible, quiéranlo o no los interesados en las dispersiones, la disgregación y el aniquilamiento. Acaso podría decirse que los Imperios muertos políticamente son, en verdad, los Imperios vivos en su más clara significación histórica, pues, limpios de todo interés material, quedan purificados de recelos ${ }^{96}$

Esta diferencia con el primer editorial de Hispania, donde no hay ninguna reivindicación expresa al nacionalcatolicismo más allá de la apelación al pasado nacional, puede explicarse por dos motivos. El primero, que el grupo al frente del Jerónimo Zurita era tan sólido que no necesitaba justificar su propia existencia con discursos sobredimensionados acerca de un pasado concreto. El Gonzalo Fernández de Oviedo y, posteriormente, la Escuela de Estudios Hispano-Americanos venían de una tradición con más corto recorrido, ya que el americanismo había tenido más fuerza en una producción intelectual unida a la diplomacia cultural, que en la propia historiografía profesional $^{97}$. Además, la Hispanidad se alzó como caballo de batalla del nacionalcatolicismo, teniendo un papel muy relevante en los discursos públicos de la cultura franquista ${ }^{98}$, lo que pudo influir en su desarrollo historiográfico.

Por ello, este proemio muestra en toda su crudeza la victoria del bando vencedor en la pugna intelectual mantenida durante las décadas precedentes. Se trata del triunfo de la Hispanidad, término que Ramiro de Maeztu resignificó vinculándolo al catolicismo y que terminó trascendiendo entre los intelectuales más conservadores. Este

\footnotetext{
${ }^{96}$ Antonio Ballesteros Beretta, "Proemio", Revista de Indias no 1 (1940): 5-6.

97 Palmira Vélez, La historiografía americanista en España, 1755-1936 (Madrid: Editorial Iberoamericana / Vervuert, 2007). En la JAE, el americanismo se institucionalizó ya en los años treinta: Salvador Bernabéu y Consuelo Naranjo, "Los estudios americanistas y la JAE", en en Tiempos de investigación: JAE-CSIC, cien años de ciencia en España coord. por Miguel Ángel PUIG SAMPER (Madrid, CSIC, 2007), 129-134.

98 Alba Fernández Gallego, "El afán de la América Hispana. La historiografía americanista en el CSIC del primer franquismo (1939-1951)", Revista de Historia Jerónimo Zurita, no 96 (2020, en prensa); Lorenzo Delgado, Imperio de papel. Acción cultural y política exterior durante el primer franquismo (Madrid: CSIC, 1992).
} 
concepto estaba vestido de paternalismo, reivindicando la supuesta tarea civilizadora de España en América. Primó una visión más conservadora y nostálgica que privilegiaba la interpretación colonial como proyección de España en el mundo ${ }^{99}$. E1 Hispanoamericanismo propulsado desde la JAE, que conllevó un interés científico y cultural en claves de igualdad, donde trataron de buscarse los nexos de unión más que las diferencias, estaba herido de muerte. En el proemio de la Revista de Indias, Beretta también desgranó los objetivos de la publicación poniendo especial énfasis en la Hispanidad, el catolicismo y el papel español en los descubrimientos. El texto mantiene un tono agresivo $\mathrm{y}$ beligerante que se fue suavizando en el americanismo posteriormente: cuando Estados Unidos se unió a las potencias aliadas en la Segunda Guerra Mundial y los países del eje quedaron derrotados, la Hispanidad adquirió un papel fundamental al asociarse a la propagación de la fe católica y la reivindicación del pasado imperial.

La revista contó con Antonio Ballesteros-Beretta como director, Ciriaco Pérez Bustamante como redactor jefe y Manuel Ballesteros-Gaibrois como secretario ${ }^{100}$. Fue más pluridisciplinar, incluyendo artículos sobre etnografía, arte o geografía ${ }^{101}$, entre otros. No es de extrañar, si tenemos en cuenta que en 1946 se creó la Escuela de Estudios Hispano-Americanos de Sevilla, con diez secciones entre las que había algunas dedicadas a Literatura, Arte, Historiografía, Geografía o Historia de las Ciencias Naturales. El peso del catolicismo fue más notable en las publicaciones sobre americanismo. El Fernández de Oviedo contaba entre sus Secciones con una dedicada en exclusivo a las Misiones. Desde 1943 se impulsó la creación de una revista llamada Missionalia Hispanica, aunque la iniciativa venía de Ibáñez Martín, quien animaba a que se recogiesen trabajos de investigación histórica acerca de la obra misionera española. Esto muestra una mayor relación entre el aparato estatal y este Instituto, quizás por amistad pero, sobre todo, por el interés que el régimen tenía en los discursos sobre el papel de España en América en relación al catolicismo, que podía utilizar en

\footnotetext{
99 José María López Sánchez, Los refugios de la derrota..., 249.

${ }^{100}$ Carta de Antonio Ballesteros al Presidente del Patronato Menéndez Pelayo, mayo de 1940. AGA. Educación. Fondo CSIC. Caja 31/8531. Carpeta Instituto Gonzalo Fernández de Oviedo.

${ }^{101}$ Hermann Trimborn, “Tres estudios para la Etnografía y Arqueología de Colombia”, Revista de Indias, 11 (1943): 43-92; Diego Angulo Íñiguez, "La Anunciación del pinto mejicano Fray Alonso López de Herrera", Revista de Indias, no 15 (1944): 121-126; Salvador García Franco, "La Geografía astronómica y Colón”, Revista de Indias, n 11 (1943): 93-116, respectivamente.
} 
una diplomacia internacional. Años más tarde esta sección se desgajó del Instituto para conformar uno independiente, el Santo Toribio de Mogrovejo. En 1943 Antonio Ballesteros apoyó la idoneidad de profundizar sobre las misiones porque "forma la parte más importante de nuestra labor civilizadora, por el hecho de haber llevado la fe a medio mundo, e ir trabada indisolublemente a la obra descubridora y colonizadora, según se consigna en el testamento de Isabel la Católica y en la política indiana de nuestros Reyes" ${ }^{102}$. A pesar de este interés y de que la revista finalmente vio la luz, las quejas sobre el presupuesto eran constantes, ya que se les otorgaba el mismo que cuando solo editaban la Revista de Indias ${ }^{103}$.

En general, los estudios muestran una aproximación a las fuentes con una intencionalidad más de difusión que de interpretación. En el caso de los "varia" de Hispania encontramos meras transcripciones de los textos acompañados de algunas indicaciones ${ }^{104}$. A través de las revistas se pretendía mostrar la labor llevada a cabo en los archivos nacionales y expandir las glorias pasadas de la nación: en el caso del Zurita con los Archivos de la Corona de Aragón y Simancas, y en el de la Sección de Estudios Hispano-Americanos en Sevilla, con el Archivo de Indias. Las revistas se confirmaron como órgano de expresión de la actividad interna. Pero también muestran las diferencias con las que las distintas escuelas historiográficas abordaron su relación con los discursos del régimen. Si bien todas estuvieron dentro de los parámetros nacionalcatólicos, algunas pudieron desarrollar su producción sin adoptar recurrentemente el discurso oficial, sirviéndose de una tradición anterior más consolidada, y otras aportaron un carácter más combativo, al tener que definir su campo historiográfico de manera propia, supeditándose a las necesidades del Estado.

\footnotetext{
102 Oficio al Secretario General del CSIC, 16 noviembre 1943. AGA. Educación. Fondo CSIC. Caja 31/8543. Carpeta Instituto Gonzalo Fernández de Oviedo.

${ }^{103}$ Carta de Ciriaco Pérez Bustamante, 8 de junio de 1945. AGA. Educación. Fondo CSIC. Caja 31/8547. Carpeta Instituto Gonzalo Fernández de Oviedo.

${ }^{104}$ Miguel Herrero, "Ratificación de profesión religiosa de Fr. Pedro González de Mendoza", Hispania, ${ }^{\circ}$ 3 (1941): 109-111; Marqués de Saltillo, "Servidores del Rey don Felipe II", Hispania, no 4(1941): 116122.
} 


\section{REFLEXIONES FINALES}

Este texto ha mostrado cómo, tras la guerra civil, se abrió la posibilidad de conformar un nuevo orden académico que terminó materializándose en la creación del CSIC. Respondió a la necesidad de crear una institucionalidad propia por parte de un Estado que surgía de un conflicto. La guerra de ocupación no terminó con el último parte de guerra: se desplegó por toda una serie de campos donde se quiso propiciar la intervención del Estado. Las instituciones académicas y de investigación fueron ocupadas, y se produjo un intento por controlar su producción. Como se ha demostrado, este plan no siempre dio sus frutos, ya que una vez conformadas las principales estructuras y repartido el poder dentro de ellas, existió lugar para la autonomía. Para este análisis concreto se ha escogido, dentro del CSIC, el campo de la historiografía. Posar la mirada sobre los investigadores que desarrollaron sus trabajos en los institutos de Historia, así como las revistas que desarrollaron, nos ha permitido comparar el discurso oficial del régimen y la institución con lo que realmente ocurría en la práctica diaria de la profesión, cuando tuvieron que enfrentarse al problema de poner en marcha los mecanismos de la producción científica.

El CSIC se enfrentó al pasado de la JAE y republicano negando cualquier vínculo con él y dejándolo fuera del nuevo orden creado. Se definió, de alguna forma, en oposición a él. Sin embargo, los discursos del Consejo no fueron nuevos, la guerra civil no fue una "hora cero", un punto de no retorno y de cambio radical. Más bien, la guerra fue el contexto en que pudieron por fin ocuparse unas instituciones académicas largamente deseadas: el conflicto latente que había enfrentado desde décadas antes distintos modelos de entender la academia y de abordar el pasado, pudo por fin resolverse a favor de los defensores de la compatibilidad entre ciencia y fe. A pesar de la ruptura intelectual con ese pasado, lo cierto es el que Consejo no dudó en apropiarse de él y de resignificarlo cuando las condiciones materiales y prácticas lo hicieron necesario. Se ocupó así el espacio físico dejado por la JAE, pero también se recurrió a estructuras internas, proyectos en marcha e incluso personal. Los objetivos de la institución rompían con el modelo anterior, pero la continuación de algunos de sus miembros propició también la de algunas de sus prácticas, anteriores a la guerra. Los tiempos del desarrollo de la vida académica se impusieron entonces al proyecto cultural. En otros casos, la duplicidad de cargos en una misma persona facilitó muchas veces el 
«Una ciencia para la verdad y para el bien ». Los historiadores del Consejo Superior de Investigaciones Científicas y la institucionalización del orden académico franquista

éxito de este proyecto y, sobre todo, la coincidencia del mismo en ámbitos distintos, como fue el caso de la educación y la ciencia, gracias a la figura de Ibáñez Martín.

El nacionalcatolicismo fue la base cultural de este nuevo orden, lo que quedó plasmado a nivel legislativo y en los actos internos del organismo. De cara al exterior, también se materializó físicamente en la denominada "ciudad de Dios", donde ciencia y fe comulgaban también en el plano arquitectónico. Sin embargo, en su dimensión pública el CSIC se enfrentó a mayores limitaciones. Sus principales actividades se hicieron normalmente en un ámbito exclusivamente académico, y la influencia que sus investigadores pudieron tener en el espacio público fue en general a título individual, y por converger en ellos otras identidades locales o políticas (como algunos miembros de Falange). Esto se ve muy claramente en la celebración del Milenario de Castilla. Sí se pretendió el contacto con la comunidad investigadora internacional, para lo cual se ha demostrado muy valioso el término de autarquía científica, entendiéndose como la voluntad de abrirse al exterior, pero sin que eso hiciera cuestionar su propio modelo.

El análisis de la producción historiográfica ha demostrado cómo a ese modelo que se creía incuestionable, muchas veces se imponía la realidad de la práctica historiográfica. A pesar de la depuración sufrida, la existencia o no de unas escuelas historiográficas sólidas condicionó la actividad diaria y el recurso a una tradición que, públicamente, se negaba. Al fin y al cabo los historiadores que ocuparon los cargos más importantes en los primeros años eran investigadores consolidados antes de la guerra en sus estructuras previas, con una red académica consolidada y una práctica historiográfica definida. Otras disciplinas menos consolidadas como el americanismo no tuvieron esas herramientas, y además confluyó en ellas una mayor utilidad pública de sus discursos para el franquismo.

Quizás entendiendo la creación de este nuevo orden académico como fruto de una ocupación y aculturación, comprendiendo el modo en que se quiso destruir y resignificar el pasado anterior, podamos entender la vigencia del tipo de discursos que se desplegaron en el 75 aniversario del Consejo. La fe ocupó en 1939 las instituciones científicas, y el modelo académico construido entonces nunca ha llegado a ser realmente cuestionado en profundidad. 


\section{BIBLIOGRAFÍA}

Acerete, Eduardo. "Formaré junto a mis compañeros. Las obras militantes del catedrático Carlos E. Corona Baratech". Jerónimo Zurita. Revista de Historia, $\mathrm{n}^{\circ}$ 93 (2018): 209-232.

Alares, Gustavo. "La conmemoración del Milenario de Castilla en 1943. Historia y espectáculo en la España franquista”. Revista Jerónimo Zurita, no 86 (2011): 8687.

Alares, Gustavo. Políticas del pasado en la España franquista (1939-1964). Historia, nacionalismo y dictadura. Madrid: Marcial Pons, 2017.

Barciela, Carlos; López, Inmaculada; Melgarejo, Joaquín; y Miranda, José Antonio. La España de Franco (1939-1975). Economía. Madrid: Síntesis, 2001.

Bernabéu, Salvador, y Naranjo, Consuelo. Tierra Firme. Madrid: Residencia de Estudiantes / Consejo Superior de Investigaciones Científicas, 2007.

--. "Los estudios americanistas y la JAE". En Tiempos de investigación JAE-CSIC, cien años de ciencia en España, editado por Miguel Ángel Puig-Samper, 129134. Madrid: Consejo Superior de Investigaciones Científicas, 2007.

Bourdieu, Pierre. Homo academicus. México: Siglo XXI Editores, 2009.

--. Capital cultural, escuela y espacio social. Madrid: Siglo XXI, 1997.

Box, Zira. "El cuerpo de la nación. Arquitectura, urbanismo y capitalidad en el primer franquismo". Revista de Estudios Políticos, no 155 (enero-marzo de 2012): 151181.

--. "La dictadura franquista: culturas políticas enfrentadas dentro del régimen vencedor". En Del franquismo a la democracia, 1936-2013, coordinado por Manuel Pérez Ledesma e Ismael Saz, 239-265. Madrid: Marcial Pons, Zaragoza: Prensas de la Universidad de Zaragoza.

Burrinn, Philippe. Fascisme, nazisme, autoritarisme. París: Le Seuil, 2000.

Camprubí, Lino. Los ingenieros de Franco. Ciencia, catolicismo y Guerra Fría en el Estado franquista. Barcelona: Crítica, 2017.

Carlton, Eric. Occupation. The policies and practices of military conquerors. London: Routledge, 2002.

Claret, Jaume. El atroz desmoche: la destrucción de la universidad española por el franquismo. Barcelona: Crítica, 2006.

--. "Cuando las cátedras eran trincheras. La depuración política e ideológica de la Universidad española durante el primer franquismo". Hispania Nova: Revista de Historia Contemporánea, $\mathrm{n}^{\mathrm{o}}$ 6, (2006). 
Delgado, Lorenzo. Imperio de papel. Acción cultural y política exterior durante el primer franquismo. Madrid: CSIC, 1992.

Díaz del Campo, Ramón Vicente, y Mantero, Martín, "El conjunto del CSIC en Madrid (1939-1949). La creación de la ciudad de Dios y la Ciencia”. En Memoria e identidades. VII Congreso da Asociación de Historia Contemporánea, coordinado por Justo Beramendi y María Xesús Baz. Santiago de Compostela: Universidad de Santiago de Compostela, 2004.

Escalona, Julio; Jular, Cristina, y Alfonso, Isabel. "El medievalismo, lo medieval y el CSIC en el primer franquismo". En El franquismo y la apropiación del pasado. El uso de la historia, de la arqueología y de la historia del arte para la legitimación de la dictadura, editado por Francisco J. Moreno Martín, 159-188. Madrid: Editorial Pablo Iglesias, 2016.

Fernández Gallego, Alba. "La construcción del Instituto Jerónimo Zurita: un estudio de caso del Consejo Superior de Investigaciones Científicas en la posguerra (19391951)". Cuadernos de Historia Contemporánea, vol. 37 (2015): 257-280.

--. "Poder académico en el Consejo Superior de Comunicaciones Científicas: una larga espera". En La alargada sombra del franquismo. Naturaleza, mecanismos de pervivencia y huellas de la dictadura, coordinador por Asunción Esteban Recio, Dunia Etura y Mateo Tomasoni, 89-109. Editorial Comares, 2019 [CD].

Fernández Gallego, Alba. "El afán de la América Hispana. La historiografía americanista en el CSIC del primer franquismo (1939-1951)". Revista de Historia Jerónimo Zurita, no 96 (2020, en prensa).

García Naharro, Fernando. "El papel de la Ciencia. Publicaciones científicas y técnicas durante el franquismo (1939-1966)". Tesis doctoral, Universidad Complutense de Madrid, 2016.

García Velasco, José, y Sánchez Ron, José Manuel. 100 JAE. La Junta para Ampliación de Estudios e Investigaciones Cientificas en su centenario. Actas del II Congreso Internacional, celebrado los días 4, 5 y 6 de febrero de 2008 (2 vol.). Madrid: Residencia de Estudiantes, 2010.

Guerrero, Salvador. "El conjunto urbano del CSIC en Madrid: retórica y experimentalismo en la arquitectura española del primer franquismo". En Tiempos de investigación: JAE-CSIC, cien años de ciencia en España, editado por Miguel Ángel Puig-Samper, 285-292. Madrid: CSIC, 2007.

Gómez Bravo, Gutmaro. "Del expediente de depuración y otras responsabilidades". En La destrucción de la ciencia en España. Depuración universitaria en el franquismo, dirigido por Luis Enrique Otero Carvajal, 149-176. Madrid: Editorial Complutense, 2006. 
González González, Manuel Jesús. "Periplo histórico del Instituto de España", en Sesión conmemorativa de la fundación del Instituto de España. Celebrada el 4 de febrero de 2009. Madrid: Instituto de España, 2010.

Hernández Burgos, Claudio. "De la cultura de guerra a la cultura de la victoria: los vencedores y la construcción de la dictadura franquista (1936-1951). Pasado y Memoria: Revista de Historia Contemporánea, $\mathrm{n}^{\circ} 15$ (2016): 123-148.

Hernández Holgado, Fernando. "La prisión militante: las cárceles franquistas de mujeres de Barcelona y Madrid (1939-1945)". Tesis doctoral, Universidad Complutense de Madrid, 2011.

Jiménez-Landi, Antonio. La Institución Libre de Enseñanza y su ambiente. Tomo III. Periodo escolar 1881-1907. Madrid: Editorial Complutense, 1996.

López Sánchez, José María. Heterodoxos españoles. El Centro de Estudios Históricos, 1910-1936. Madrid: Marcial Pons Historia / Consejo Superior de Investigaciones Científicas, 2006.

--. "Ciencia y cultura en el Centro de Estudios Históricos de Madrid, 1910-1936”. Circunstancia: Revista de Ciencias Sociales del Instituto Universitario de Investigación Ortega y Gasset, no 14 (2007).

--. "Los estudios históricos en la Facultad de Filosofía y Letras". En La Facultad de Filosofía y Letras en la Segunda República. Arquitectura y universidad durante los años treinta, coordinado por Santiago López Ríos y Juan Antonio González Cárceles, 408-415. Madrid: Universidad Complutense de Madrid-Sociedad Estatal de Conmemoraciones Culturales, 2008.

--. Los refugios de la derrota. El exilio cientifico e intelectual republicano de 1939. Madrid: Consejo Superior de Investigaciones Científicas / Los Libros de la Catarata, 2013.

--. "La medicina en la universidad nacionalcatólica”. En La Universidad nacionalcatólica. La reacción antimoderna, dirigido por Luis Enrique Otero Carvajal, 317-476. Madrid: Dyckinson, 2014.

--. "El árbol de la ciencia El árbol de la ciencia nacionalcatólica: los orígenes del Consejo Superior de Investigaciones Científicas". Cuadernos de Historia Contemporánea, 38 (2016): 171-184.

--. "Científicos e intelectuales, una nueva cultura política: José Cuatrecasas y las colecciones de flora tropical". Asclepio. Revista de Historia de la Medicina y de la Ciencia 71/2 (2019): 277-291.

Marín Gelabert, Miquel. "Historiadores locales e historiadores universitarios. La historiografía española en su contexto internacional, 1948-1965”. En Lecturas de la Historia. Nueve lecciones sobre Historia de la Historiografía, coordinado por 
Carlos Forcadell e Ignacio Peiró, 97-149. Zaragoza: Institución Fernando E1 Católico, 2001.

--. Los historiadores españoles en el franquismo, 1948-1975. La historia local al servicio de la patria. Zaragoza: Prensas Universitarias: Institución Fernando el Católico (CSIC), 2005.

--. "Revisionismo de Estado y primera hora cero en España, 1936-1943". En El pasado en construcción. Revisionismos históricos en la historiografía contemporánea, editado por Carlos Forcadell, Ignacio Peiró y Mercedes Yusta, 363-406. Zaragoza: Institución Fernando el Católico, 2015.

Martínez Sánchez, Santiago. "Los obispos españoles ante el Opus Dei, 1939-1946”. Studia et Documenta: Rivista dell'Istituto Storico san Josemaría Escrivá, vol. XIV, no 14 (2020): 217-286.

Mata, Santiago. "Leopoldo Eijo y Garay (1878-1963)". Tesis doctoral, Universidad de Navarra, 1996.

Morente Valero, Francisco. "La universidad fascista y la universidad franquista en perspectiva comparada". Cuadernos del Instituto Antonio de Nebrija de Estudios sobre la Universidad, $\mathrm{n}^{\mathrm{o}} 8$ (2005): 179-214.

Otero Carvajal, Luis Enrique. "La universidad nacionalcatólica". En La Universidad nacionalcatólica. La reacción antimoderna, dirigido por Luis Enrique Otero Carvajal, 69-129. Madrid: Dyckinson, 2014.

Oviedo Silva, Daniel, y Pérez-Olivares, Alejandro. Madrid, una ciudad en guerra (1936-1948). Madrid: Los libros de la Catarata, 2016.

Pallol, Rubén. "La Filosofía en la universidad nacionalcatólica". En La Universidad nacionalcatólica. La reacción antimoderna, dirigido por Luis Enrique Otero Carvajal, 477-534. Madrid: Dyckinson, 2014.

--. "La Historia, la Historia del Arte, la Paleografía y la Geografía en la universidad nacionalcatólica". En La Universidad nacionalcatólica. La reacción antimoderna, dirigido por Luis Enrique Otero Carvajal, 535-683. Madrid: Dyckinson, 2014.

--. "Menéndez contra Menéndez. Represión y resistencia de los discípulos de Menéndez Pidal ante la ofensiva intelectual tradicionalista de posguerra en la universidad española”. Cuadernos de historia contemporánea, 38 (2016): 285299.

--; San Andrés Corral, Javier; y Fernández Gallego, Alba. "De asaltos y conquistas. El papel de las redes en las oposiciones a cátedras de universidad en el primer franquismo (1940-1951)". En La alargada sombra del franquismo. Naturaleza, mecanismos de pervivencia y huellas de la dictadura, coordinador por Asunción 
Esteban Recio, Dunia Etura y Mateo Tomasoni, 1000-1022. Editorial Comares, 2019 [CD].

Pasamar, Gonzalo. "Cultura católica y elitismo social: la función política de Arbor en la posguerra española". Arbor. Ciencia, pensamiento y cultura, 479-480 (1985): 17-38.

--. "Oligarquías y clientelas en el mundo de la investigación científica; el Consejo Superior en la universidad de posguerra". En La universidad española bajo el régimen de Franco: Actas del Congreso celebrado en Zaragoza entre el 8 y 11 de noviembre de 1989, coordinado por Juan José Carreras, 305-339. Zaragoza: Institución Fernando el Católico, 1991.

--. Historiografía e ideología en la postguerra española: la ruptura de la tradición liberal. Zaragoza: Prensas Universitarias, 1991.

Pasamar, Gonzalo y Peiró, Ignacio. Historiografía y práctica social en España. Zaragoza: Universidad de Zaragoza, 1987.

Peiró, Ignacio. Historiadores en España. Historia de la Historia y memoria de la profesión. Zaragoza: Prensas de la Universidad de Zaragoza, 2013.

Peiró, Ignacio y Pasamar, Gonzalo. Diccionario Akal de historiadores españoles contemporáneos. Madrid: Akal, 2002.

Peña González, José. "El Instituto de España: pasado y presente". Boletín de la Real Academia de Córdoba de Ciencias, Bellas Letras y Nobles Artes, $\mathrm{n}^{\circ} 153$ (2007): 301-303.

Pérez-Olivares, Alejandro. "Objetivo Madrid: planes de ocupación y concepción del orden público durante la guerra civil española". Culture \& History Digital Journal, $\quad \mathrm{n}^{\mathrm{o}} 4 \quad$ (2), (2015). Disponible online en http://cultureandhistory.revistas.csic.es/index.php/cultureandhistory/article/view/ $\underline{84 / 298}$.

--. "La victoria bajo control: ocupación, orden público y orden social del Madrid franquista (1936-1948)". Tesis doctoral, Universidad Complutense de Madrid, 2017. Disponible online en https://eprints.ucm.es/45481/

--. "El franquismo, ¿un régimen de control? Experiencias, dispositivos y espacios (desde el Madrid ocupado)". Historia Social, no 97 (2020): 61-78.

--. Madrid cautivo. Ocupación y control de una ciudad (1936-1948). Valencia: PUV, 2020.

Pérez-Olivares, Alejandro y Gómez Bravo, Gutmaro. "Las lógicas de la violencia en la guerra civil: balance y perspectivas historiográficas”. Studia Historica. Historia Contemporánea, $\mathrm{n}^{\mathrm{o}} 32$ (2014): 251-262. 
Píriz González, Carlos. "En campo enemigo: la Quinta Columna en la Guerra Civil española (c. 1936-1941)". Tesis doctoral, Universidad de Salamanca, 2019.

Prades Plaza, Sara. "Escribir la historia para definir la nación. La historia de España en Arbor, 1944-1956". Ayer, no 66 (2007): 177-200.

--. "Discursos históricos e identidad nacional: la Historia de España del nacionalcatolicismo franquista”. En La nación de los españoles. Discursos y prácticas del nacionalismo español en la época contemporánea, editado por Ismael Saz y Ferrán Archilés, 55-79. Valencia: Publicaciones de la Universitat de València, 2012.

--. España y su Historia. La generación de 1948. Valencia: Publicacions de la Universitat Jaume I, 2014.

Reol Tejada, Juan Manuel. "El Instituto de España y las Reales Academias". Arbor: Ciencia, pensamiento y cultura, $\mathrm{n}^{\mathrm{o}} 641$ (1999): 1-18.

Ricoeur, Paul. La memoria, la historia, el olvido. Madrid, Trotta, 2010.

San Andrés Corral, Javier. "El Derecho Político en la universidad nacionalcatólica". En La Universidad nacionalcatólica. La reacción antimoderna, dirigido por Luis Enrique Otero Carvajal, 775-896. Madrid: Dyckinson, 2014.

Santoveña Setién, Antonio. "Una alternativa cultural católica para la España de la Restauración: Menéndez Pelayo y la polémica sobre la ciencia”. Investigaciones históricas: Época moderna y contemporánea, 12 (1992): 235-254.

Saz, Ismael. España contra España. Los nacionalismos franquistas. Madrid: Marcial Pons, 2003.

--. "Falangistas y católicos reaccionarios: una batalla político-cultural decisiva". En La España de los cincuenta, editado por Abdón Mateos, 237-250. Madrid: Eneida, 2008.

--. "Las culturas de los nacionalismos franquistas". Ayer, no 71 (3/2008): 153-174.

Steenkamp, Christina. Violence and Postwar Reconstruction. Managing Insecurity in the Aftermath of Peace Accords. London : New York, Tauris, 2009.

Varela, Javier. La novela de España. Los intelectuales y el problema español. Madrid: Taurus, 1999.

Vélez, Palmira. La historiografía americanista en España, 1755-1936. Madrid: Editorial Iberoamericana / Vervuert, 2007.

Vittoria, Albertina. “L’Università italiana durante il regime fascista, controllo governativo e attività antifascista”. En La universidad española bajo el régimen de Franco (1939-1975), editado por Juan José Carreras y Miguel Ángel Ruiz Carnicer, 29-62. Zaragoza: Institución Fernando el Católico, 1991. 